\title{
The limits of gender and regional diversity in the European Association of Social Psychology
}

\author{
Boglárka Nyúl $^{1} \quad$ Nóra Anna Lantos ${ }^{1} \quad$ Stephen D. Reicher ${ }^{2} \quad$ Anna Kende ${ }^{1}$
}

${ }^{1}$ ELTE Eötvös Loránd University, Budapest, Hungary

${ }^{2}$ St. Andrews University

Correspondence

Boglárka Nyúl, ELTE Eötvös Loránd University, Budapest, Izabella utca 46, 1064 Budapest, Hungary.

Email:nyul.boglarka@ppk.elte.hu

The article was submitted to and reviewed by the 2017-2020 Editorial team.

\begin{abstract}
Academic associations define the scientific standards and affect individual academic careers within a discipline. The European Association of Social Psychology (EASP) was founded in 1966 to become an association for all social psychologists in Europe. However, this was unattainable during the Cold War, and more subtle obstacles, such as women's underrepresentation in academia, prevented EASP from due representation of all social psychologists. Social psychological theory offers insights into why social hierarchies are maintained and how they can be dismantled. We used the case of EASP to analyse challenges to creating a diverse and inclusive association by analysing membership data, participation, distinction and influence throughout the organisation's history (1966-2020) and conducting a more in-depth analysis for the 2011-2017 period. We found a glass-ceiling effect for women and a persistent underrepresentation of non-Western European scholars on all levels. We conclude that increasing diversity requires more fundamental changes to overcome structural inequalities.

KEYWORDS

academic organisation, diversity, divided Europe, EASP, gender equality
\end{abstract}

\section{1 | INTRODUCTION}

\subsection{The limits of gender and regional diversity in academia: The case of the European Association of Social Psychology}

The European Association of Social Psychology (EASP) was established in 1966 with the aim of improving the status of social psychology in Europe. International collaborations among European social psychologists were not common at the time, and the first international conference for European researchers was held only in 1963. This Conference paved the way to a more comprehensive programme for social psychology in Europe and eventually led to the establishment of the European Association of Experimental Social Psychology (EAESP, Van Avermaet, 2017).
The initial objective of EAESP (later renamed to EASP) was to improve the overall status of social psychology in Europe (in comparison to North American social psychology). To achieve this goal, they attempted to bring together social psychologists from different European regions to overcome deep political divisions, and to become an association of all social psychologists of Europe (Graumann, 1995; Tajfel, 1972). The establishment of the East-West meetings in 1967 indicated an early commitment to diversity and this effort was invaluable only a decade after the end of a severe witch-hunt against psychologists during the Stalinist period in Eastern Europe (see e.g., Razran, 1958; Zajonc, 1957). In the 1960s, imprisoned psychologists were released, psychological training and research institutions were reinstated and psychology was no longer labelled as ideological and the enemy of the state. This opened up the need to redefine internationalisation of psychology within the socialist states and to adapt to Western

This is an open access article under the terms of the Creative Commons Attribution-NonCommercial-NoDerivs License, which permits use and distribution in medium, provided the original work is properly cited, the use is non-commercial and no modifications or adaptations are made.

(c) 2021 The Authors. European Journal of Social Psychology published by John Wiley \& Sons Ltd. 
standards of science. To overcome language barriers, major research articles could be submitted to the European Journal of Social Psychology in French and German (and translated into English upon acceptance) (Van Avermaet, 2017).

Thirty years after the fall of communism when objective barriers are no longer in place, we take a look at the status of diversity within EASP and establish trends in the more than 50 years of its history. Importantly, there is now empirical evidence that the inclusion of multiple voices and increased diversity improves the quality of science (see e.g., Jimenez et al., 2019; Maher \& Tetreault, 2009). Furthermore, we have a better and more critical understanding of the effects of the globalised and neoliberal academic context on knowledge production and on the preservation of existing status hierarchies (see Hanafi, 2016). Specifically, scientific standards, accepted and adopted worldwide as 'international', are largely determined by anglophone and Western institutions and reflect their own dominant practices against which all research is compared (for the influence of internationalisation on science in 'nonhegemonic' countries, see Losego \& Arvanitis, 2008).

Striving for diversity in academia and within academic organisations is not only essential for science, it is also a moral duty in line with the values of inclusion, equality, universalism and multiculturalism. Although these values may not be shared by all social scientists to the same degree, they are often considered 'European values' (European Commission, 2021), and they guide social psychological research. Social psychology, especially the study of intergroup relations, offers evidence on processes of intergroup bias, explicit and implicit forms of discrimination, and suggests ways to decrease bias, and create more inclusive, egalitarian and fair societies. At the same time, we must keep in mind that social psychologists also have their 'blind spots' in their perception (Banaji \& Greenwald, 2016), so we may not notice bias within our own community. We have to reflect on the issue of diversity among ourselves (see also Ernst-Vintila et al., 2016).

Social psychological science can offer explanations for why some efforts are successful and others are not. Diversity efforts can fail when measures do not take into account long-standing and ongoing structural inequalities (e.g., Wright et al., 2007), they do not consider hidden biases that direct people's decisions (Fleras, 2016), or when policies claim to ensure equal opportunities, but end up reproducing inequalities (see colour-blind approaches Malat et al., 2010, or policies guided by meritocracy beliefs, Au, 2014).

Apart from regional diversity, which was recognised as a challenge already at the time of the foundation of EASP, we look at gender diversity, which was formally recognised as an area for improvement in the second decade of 2000 (EASP, 2018; in the Code of Conduct and Diversity Statement EASP, 2018) and at conferences (e.g., Derks et al., 2018; Wood \& Sczeszny, 2017). However, it has been a more broadly recognised issue within academia in the past decades (see e.g., Bagilhole \& White, 2013; Valian, 2005) compared to regional diversity. The purpose of the analysis is both applied and theoretical. The applied characteristic of the analysis is that we aim to offer an accurate description of the status quo of the organisation, based on which EASP leadership can make informed decisions to increase diversity more effectively. The theoretical implication of the work is that using social psychological concepts we explain how structural inequalities are reproduced (vs. overcome) in academic organisations (or learned societies) by showing the intricate interplay between individual, institutional and societal processes.

Academic associations have a profound effect on their discipline, as shown by a case study of the UK Political Studies Association (Awesti et al., 2016) and the case study of the Regional Studies Association (Hopkins, 2011). These organisations create norms for the academic discipline by defining the conditions of membership, by maintaining journals and electing their Editorial Boards, and by rewarding research practices and researchers through support and recognition. Members have obligations toward the society, for example, by complying to ethical standards and paying fees, but also enjoy benefits, such as access to conferences, publications or grants. Therefore, academic associations can affect personal lives, but also shape their discipline in every possible way, especially within their designated geographical location, but often also beyond. Academic associations accept some representatives among their members, giving them the chance to participate in activities and build their personal academic networks, offering direct or indirect financial support, giving them awards at different career stages. Journals define the acceptable versus unacceptable forms of research in terms of methods, themes and the language of knowledge production. These mechanisms put some groups and some types of scientific work in a privileged position compared to others and academic associations have a great influence on these practices. In sum, analysing diversity within EASP can offer insights into the challenges of addressing structural inequalities embedded in academia, and the biases in the systems of knowledge production that spans beyond EASP and social psychology.

\subsection{Gender bias in academia}

The representation of women in various disciplines and academic ranks has gone through a remarkable change in the past decades. However, there are still disproportionally fewer women among senior or topranked academics than men (see e.g., Shen, 2013). Gender inequality in academia has been compared to the seven-headed dragon (Van den Brink \& Benschop, 2012) to highlight the different ways in which inequality creeps back despite the efforts that have been made to achieve change. The dragon metaphor highlights that the introduction of some gender equality practices end up sustaining gender inequality because they fail to address structural inequalities. Although legal obstacles and explicit forms of sexism have been lifted, both subtle forms of sexism and structural causes connected to gender relations in society (e.g., Williams, 2005) continue to operate in ways that create barriers to gender equality in academia (see e.g., in letters of recommendation in Madera et al., 2019, linguistic bias against women in selection procedures see Rubini \& Menegatti, 2014). Furthermore, these external factors and societal norms affect women's choices as well (e.g., not striving for high positions because of expected conflicts and trade-offs) and keep them from equally succeeding in academia (Eagly \& Miller, 2016; Gino et al., 2015). Even when women successfully 
enter senior positions, they face the problem of not fitting the position due to masculine occupational stereotypes, which increase the likelihood of giving up (Peters et al., 2012a).

Structural inequalities are justified by ideologies that compel women to invest more in child and elder care, so putting them at a disadvantage in the domain of paid work (Stone, 2007), and even 'family friendly' policies have career penalties (Barreto et al., 2009). Inequalities are also justified by a perceived mismatch between women and high-status positions that are manifested in the functioning of organisations, such as the division of labour, the symbols and language, and the patterns of interactions (Martin, 2003; Ridgeway, 1997). Men (and women) often doubt women's abilities in certain jobs, especially in high status areas and positions (Erickson et al., 2000), and the belief that only men can be brilliant is present even among 6-year-old children (Bian et al., 2017). Moreover, fields where brilliance is perceived as a necessity for success are occupied by fewer women (Leslie et al., 2015) and women feel dissimilar to people holding these positions (Bian et al., 2018). Women often refrain from participating in networking because this would mean overstepping gendered expectations about femininity (Roth, 2004). Women of lower academic rank speak less at scientific conferences compared to men with the same ranks. For example, although women's underrepresentation as speakers disappeared over time in symposia chaired by women, their ratio remained one third in symposia with male chairs, suggesting that chairs can function as gatekeepers (Johnson et al., 2017). All of these factors contribute to lower representation, less access to resources and lower scientific impact. In summary, while the importance of gender equality in specific academic contexts has been broadly recognised, efforts to combat gender inequality have reached uneven results across different disciplines and across the different levels of the academic hierarchy.

\subsection{Regional bias in academia}

Challenges of diversity are not limited to the representation of women across academic ranks. Diversity also means the inclusion of people with diverse backgrounds, such as their race, ethnicity, culture, social class, religion, sexual orientation, among others. All of these areas are affected by institutionalised forms of racism and prejudice (e.g., Wright et al., 2007), structural inequalities embedded in society and in neoliberal academic institutions (Giroux, 2015), the often invisible, yet powerful subtle biases (e.g., Fleras, 2016). Because this kind of data was not available for the present analysis, their discussion falls outside the current article to directly address. However, there is one area of diversity that is especially relevant for geographically defined academic associations: regional diversity.

Academic associations strive to represent, regulate and advance their academic discipline through maintaining a geographically defined (national, international, European, Asian, etc.) membership. Paradoxically, the lack of regional diversity within academia and social psychology in particular is a rather neglected or even implicitly accepted phenomenon: few studies have tried to address the problem before (for some recent exceptions, see Ernst-Vintila et al., 2016 on diversity within EASP, and Saab et al., 2020 on questions connected to Arabic social psychology).

There are both subjective and objective obstacles of internationalisation. Scholars from different regions have different educational backgrounds, research interests, expertise and experience and they speak different languages, all of which can create obstacles for inclusion and international academic recognition. Because Europe has always been a politically and economically divided continent and these divisions have a profound influence on higher education and academic research, regional diversity creates multiple obstacles. For example, fluency in English, either because of being a native speaker or because of broadly available and high-quality language training in schools, provides an important advantage to people working in English speaking and Western European countries and creates another layer of inequalities between regions. With the hegemony of English language scientific publications, editors and reviewers can be sceptical about the scientific merit of a paper not written in 'proper' English, whereas proofreading and copy-editing services are expensive and often unaffordable for non-English speaking authors. The lack of accessible translation and proofreading services and the expectation of manuscripts written in impeccable English is an important source of regional inequality created by publishers in an era of continuously growing publication expectations for academic recognition and career advancement.

Ironically, social psychology as a discipline has been concerned with the problem that lack of diversity creates for science since the 1960s (for the critique of using student samples, see Henry, 2008; McGuire, 1967; Sears, 1986). The overrepresentation of research conducted in WEIRD (Western, educated, industrialised, rich and democratic) contexts identifiably led to false generalisations about psychological processes (Heinrich et al., 2010). In line with these tendencies in empirical research, there is a growing consensus that considering high status groups (i.e., groups that are most similar to the background of the researchers themselves) as the default human experience distorts our understanding of human behaviour (Hegarty \& Bruckmüller, 2013). In sum, the uneven regional representation of European social psychologists within the Association can directly affect social psychological theories and the discipline on the whole.

The political changes that have taken place since the foundation of the Association continue to bring about new obstacles for equal access for researchers coming from different regions. Undoubtedly, the fall of communism removed the greatest objective barrier of internationalisation, and EU enlargement created unprecedented potentials for increasing regional diversity in research in the history of Europe. However, the rapid growth in international mobility within Europe (Altbach \& Knight, 2007) created new problems, and countries benefited from this new level of mobility unevenly. For example, it facilitated the so called 'brain drain' phenomenon, that is, a unidirectional pattern of migration impoverishing academic institutions in poorer countries (Cervantes \& Guellec, 2002; Horvat, 2004; Saravia \& Miranda, 2004).

Specific regions of Europe are affected by different types of obstacles, the detailed analysis of which falls outside the scope of the current article to adequately address. However, it is clear that economic and linguistic barriers, differences in training and academic traditions, 
4I WILEY $\pitchfork S$

methods and topics of interests appear in different combinations in the regions that are less represented in mainstream social psychology in Europe. Economic disadvantages and language barriers are most pronounced in Eastern Europe (former socialist countries) but are also present in Southern Europe. The lower representation of scholars from Northern Europe in European social psychology may have more to do with the lack of traditions within the field of social psychology, given that scholars in this region do not face political, economic or linguistic hardships.

\section{2 | THE PRESENT RESEARCH}

We examined trends in diversity within EASP to ask how successful such efforts are in overcoming previous inequalities. We analysed diversity with a focus on two domains: gender and region. The practical reason for this was the availability of data, and the fact that they are explicitly mentioned by the organisation as relevant domains of diversity (EASP, 2018).

In contrast to gender equality, which was not raised as an issue until recently, regional diversity was an explicit objective of the organisation at the time of its foundation. However, when the objective obstacles created by the Cold War were lifted, it became apparent that the challenges of equal regional representation have not disappeared. Moscovici, one of the founders of the Association stated that social psychologists must strive for independence and freedom in thinking and they should take advantage of the diversity of people, cultures and ideas to reflect on social problems (Moscovici, 1997). The geocultural diversity of the Association has been investigated earlier, when a decrease in regional diversity was identified. The decline was explained by the tendency of favouring one language (English) and one methodology (experiments) over others within the Association (Ernst-Vintila et al., 2016). In the present study we investigated questions of diversity by looking at indicators of inclusion (membership and participation) and distinction and influence (awards, executive committee membership and Editorial Boards).

\subsection{Data}

We categorised data of different levels of inclusion and distinction represented in a pyramid (see Figure 1). The bottom of the pyramid consists of membership information; the second level is participation in the events and actions, such as meetings and grant schemes. The top of the pyramid consists of different forms of distinction and influence: awards and membership in the leading bodies of the organisation and the Editorial Boards of the journals of the Association.

Most of the data presented in this article was accessed originally for the EASP Diversity Report (https://www.easp.eu/getmedia.php/ media/easp/201806/374v0-orig.pdf). We supplemented the data provided by EASP with publicly available information and individual requests to event organisers. However, not all data was available for the same time periods, therefore, for the ease of understanding, Table 1

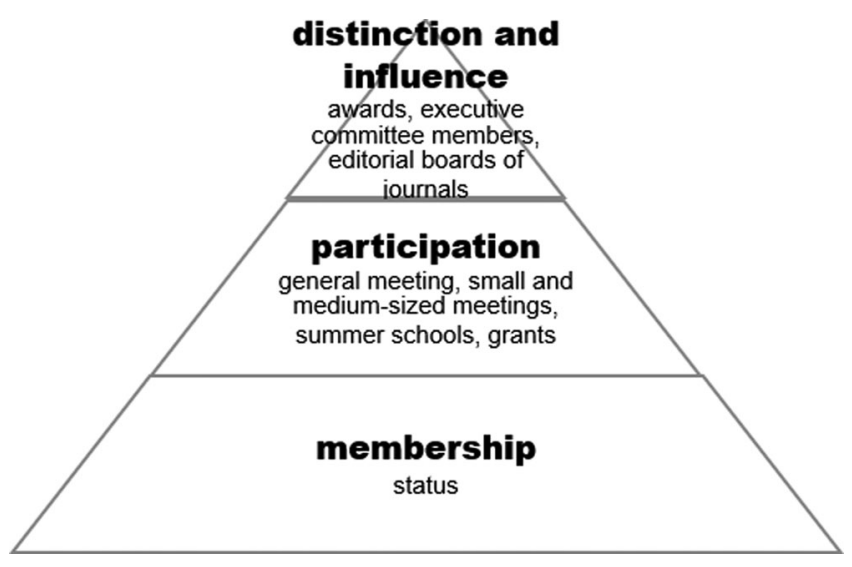

FIGURE 1 Levels of inclusion and distinction

summarises the data used. We conducted an in-depth analysis for a 7year time period between 2011 and 2017 to get an accurate picture of the relatively recent status quo.

\subsection{1 | Data on membership}

EASP has three membership categories: postgraduate, full and affiliate membership. Postgraduate members are current PhD students in social psychology and can remain in this category for four years regardless of acquiring a $\mathrm{PhD}$ or not. Full members hold a $\mathrm{PhD}$ in social psychology and have published at least one social psychological article in an international peer-reviewed journal. Affiliate membership is available to social psychologists working outside Europe, although these scholars have had the option to become full members since 2012.

\subsection{2 | Data on participation}

We analysed participation in the 2014 Amsterdam General Meeting, and in the 2017 Granada General Meeting as these events took place within the examined time period and we had access to quite detailed information about meeting participants. We divided attendance by type of presentation (symposium, thematic, blitz and poster presentation) as they tend to have different levels of prestige (exemplified by the fact that symposium presentations are often rejected and accepted as a blitz talk or poster, but not the other way around). We also examined participation in small and medium-sized EASP meetings in three years (2015-2017) and two summer schools (2014 and 2016) that fell within the examined time period and participant information was available. Although non-members can attend meetings organised by EASP, we present information only on members in order to be able to compare their ratio to the overall membership as a baseline. We examined grant recipients between 2015 and 2017 comparing to the baseline. Additionally, we report information about meetings, summer schools and grants for the period between 2018 and 2020; however, in the absence of membership data, we did not compare these to the baseline membership. 
TA B LE 1 Different data sources used and examined period in the analyses

\begin{tabular}{|c|c|c|c|c|}
\hline & Type of information & Period & Points of analysis & Source of information \\
\hline \multirow{2}{*}{$\begin{array}{l}\text { Membership } \\
\text { information }\end{array}$} & Gender, residence & $1968,2011-2017$ & Yearly & EASP \\
\hline & Membership status & 2011-2017 & Yearly & EASP \\
\hline \multirow[t]{4}{*}{ Participation } & $\begin{array}{l}\text { General Meeting in Amsterdam } \\
\text { and Granada }\end{array}$ & 2014,2017 & Per event & Programme outline \\
\hline & Small and medium-sized meetings & $2015-2020$ & Per event & Organisers, EASP website \\
\hline & Summer schools & $2014,2016,2018,2020$ & Per event & Organisers \\
\hline & $\begin{array}{l}\text { Grants (travel grants, 'seedcorn' } \\
\text { research grants, pre-registered } \\
\text { research, research knowledge } \\
\text { transfer scheme and } \\
\text { extraordinary grants) }\end{array}$ & $2015-2020$ & Yearly & EASP website \\
\hline \multirow{6}{*}{$\begin{array}{l}\text { Distinction and } \\
\text { influence }\end{array}$} & EC membership & $1966-2020$ & 3-year intervals & EASP website \\
\hline & EJSP Editorial Board members & $1990-2020$ & 4-year intervals & $\begin{array}{l}\text { Publications, hard copies, } \\
\text { current Editors }\end{array}$ \\
\hline & ERSP Editorial Board members & $1992-2020$ & Approx. 10-year intervals & $\begin{array}{l}\text { Publications, hard copies, } \\
\text { current Editors }\end{array}$ \\
\hline & Awards & $1984-2020$ & Yearly or 3-year intervals & EASP website \\
\hline & EJSP first authors & $2011-2020$ & Per volume & EJSP website \\
\hline & ERSP first authors & $2011-2020$ & Per volume & ERSP website \\
\hline
\end{tabular}

\subsection{3 | Data on distinction and influence}

We examined award recipients as domains of distinction and positions in committees and Editorial Boards as domains of influence. We used the broadest timespan to cover the full history of EASP (for details about the data, see Table 1). Editorial Boards of the the European Journal of Social Psychology and the European Review of Social Psychology were examined between 1990 and 2020. The Executive Committee (EC) is the de facto leadership of the Association, deciding on priorities, conference locations, grants and financial issues, which we examined for the entire history of the Association (1966-2020). We examined award recipients from those receiving the most junior to the most senior awards from the foundation of these awards in 1984 until 2020. All awards are offered every three years with the exception of the most junior award (Early Career Best Manuscript Award), which is offered every year for the best paper published in the European Journal of Social Psychology by an early career scholar. The most senior award is the Henri Tajfel Medal, which recognises a distinguished lifetime achievement contribution by a full member of the Association. ${ }^{1}$ There are four additional awards for various achievements (for a more detailed description, see www.easp.eu). Furthermore, we present descriptive data on the gender ${ }^{2}$ and the country of the institutional affiliation of the first authors of published papers

\footnotetext{
1 The award was renamed in 2019. For more information, see https://www.easp.eu/news/itm/ renaming_the_tajfel_award-947.html.

2 We coded gender using binary categories based on first names, and looked up names in cases where it was not easy to determine. We recognise that this system is not entirely accurate, and in some instances, the external category may not match identification. We interpret the findings with this potential limitation in mind.
}

in the European Journal of Social Psychology and the European Review of Social Psychology between 2011 and 2020.

\subsection{Analytic strategy}

Relying on membership data as a baseline for the period of 20112017 enabled us to investigate representation in the different levels of the Association in comparison to the overall membership. Gender was analysed as a binary concept because of the way gender is recorded in membership data. We used members' institutional affiliation as the data on region, because regional inclusion is reflected by where a person works rather than by a person's origin. This is not to say that country of origin is of no relevance, but we consider this as a separate question for analysis that was beyond the scope of this article to analyse. We categorised countries into four regions: Western, Eastern, Northern and Southern Europe, and additionally we created a category for out of Europe. It must be noted that 'out of Europe' does not reflect the diversity that may come from accepting members from all over the world, as members from outside Europe come predominantly from WEIRD countries, such as USA, Canada, Australia and Israel, with very few members from other countries. We used a geopolitical categorisation that mostly overlaps with geography but takes political and historical similarities into account. For this reason, we included all former socialist countries in Eastern Europe (including the Northern Baltic and Southern Balkan states). However, to simplify the complex comparisons, in most analyses we grouped together all non-Western European countries and compared them to Western Europeans, leaving out members from outside Europe (for the list of countries in each regions see Appendix A). 


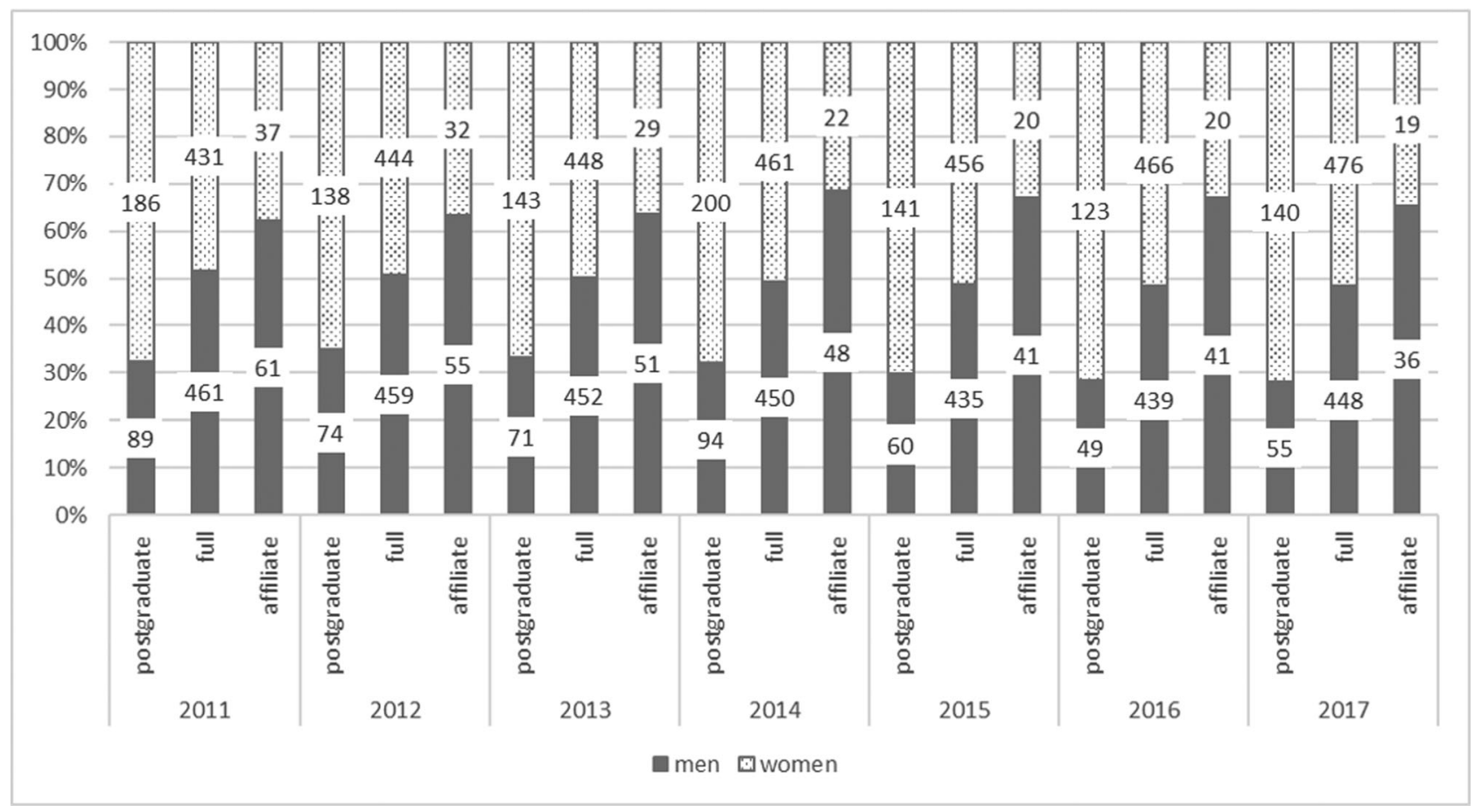

FIGURE 2 Gender and membership status between 2011 and 2017

Data analysis comprised three parts. The first information on diversity was the ratio of men and women, and the ratio of members from different regions throughout the years between 2011 and 2017. Additionally, we present descriptive data on articles published in the two journals of the Association: the European Journal of Social Psychology (EJSP) and the European Review of Social Psychology (ERSP) between 2011 and 2020, on Editorial Boards of EJSP and ERSP and on members of the Executive Committee (EC) from the beginning of the 1990s, and data on all award winners from 1966 to 2020.

Secondly, in order to identify under- or overrepresentations in terms of gender and region, we used Chi-square tests, comparing data on the different levels of inclusion with membership information from the given year as a baseline in the analysis. Specifically, if the rate of women and the rate of non-Western European researchers in a particular type of participation is lower than the rate of women or rate of non-Western researchers within the membership, it reflects underrepresentation. Data on distinction and influence was not compared to the baseline because their numbers are too low for meaningful statistical comparisons, and they are covered outside the 2011 and 2017 period as well in the analysis.

Thirdly, we extended our analysis to the period 2018-2020 and included data on meetings, grants and indicators of distinction. However, in the absence of membership data for this period, we did not make the statistical analysis of over- or underrepresentation for this period and only offer descriptive statistics. We used this data to reflect on the current status quo following the introduction of new policies by EASP.

\section{3 | RESULTS}

\subsection{Gender diversity}

\subsection{1 | Membership}

The number of female members was consistently higher than the number of male members between 2011 and 2017. There were twice as many women than men in 2011 among postgraduate members, and the gap became even greater by 2017 in favour of women. However, this gap virtually disappears when it comes to full membership (see Figure 2), resulting in an approximately equal number of men and women among full members. This can be explained by the higher dropout rate among women than men, that is, 432 (70.7\% of the original members of 2011) men, but only 391 (59.8\%) women maintained their membership between 2011 and 2017.

\subsection{2 | Participation}

At the 2014 General Meeting in Amsterdam more female members participated than male members. When we compare this number to the baseline (overall membership in 2014) women are significantly overrepresented at the meeting. However, when the ratio of postgraduate and full members is analysed separately, there was no such overrepresentation. It seems that the higher ratio of women reflected the higher presence of postgraduate members at the conference (see Table 2). 
TA B LE 2 Comparison of participation by gender in general meetings (based on presentation type), in small and medium-sized group meetings, summer schools and grant schemes between 2014 and 2017

\begin{tabular}{|c|c|c|c|c|c|}
\hline & & Women & Men & $x^{2}$ & $p$ \\
\hline \multicolumn{6}{|c|}{ Amsterdam GM (2014) Participation } \\
\hline & From all membership types & $313(57.4 \%)$ & $232(42.6 \%)$ & 5.71 & .017 \\
\hline & From postgraduate members & $123(66.8 \%)$ & $61(33.2 \%)$ & 0.31 & .575 \\
\hline & Baseline (2014) & $200(68 \%)$ & $94(32 \%)$ & & \\
\hline \multicolumn{6}{|c|}{ Presentation type } \\
\hline & Symposium & $107(50.5 \%)$ & 105 (49.5\%) & 6.87 & .009 \\
\hline & Attendance & $313(57.4 \%)$ & $232(42.6 \%)$ & & \\
\hline & Thematic presentation & $70(63.1 \%)$ & $41(36.9 \%)$ & 1.81 & .179 \\
\hline \multicolumn{6}{|c|}{ Granada GM (2017) Participation } \\
\hline & From all membership types & $392(56 \%)$ & $308(44 \%)$ & & \\
\hline & Baseline (2017) & $635(54.1 \%)$ & $539(45.9 \%)$ & 2.55 & .110 \\
\hline & From postgraduate members & $92(73 \%)$ & $34(27 \%)$ & & \\
\hline & Baseline (2017) & $140(71.8 \%)$ & $55(28.2 \%)$ & 0.26 & .609 \\
\hline & From full members & $291(52.6 \%)$ & $262(47.4 \%)$ & & \\
\hline & Baseline (2017) & $476(51.5 \%)$ & 448 (48.5\%) & 0.68 & .411 \\
\hline \multicolumn{6}{|c|}{ Presentation type } \\
\hline & Symposium & $225(50.2 \%)$ & $223(49.8 \%)$ & & \\
\hline \multirow[t]{2}{*}{2015} & Participants & 69 (65.1\%) & 37 (34.9\%) & 6.29 & .012 \\
\hline & Baseline (2015) & $617(53.5 \%)$ & $536(46.5 \%)$ & & \\
\hline \multirow[t]{2}{*}{2016} & Participants & 23 (51.1\%) & 22 (48.9\%) & 0.11 & 741 \\
\hline & Baseline (2016) & 609 (53.5\%) & $529(46.5 \%)$ & & \\
\hline \multirow[t]{2}{*}{2017} & Participants & 48 (62.3\%) & 29 (37.7\%) & 2.26 & .133 \\
\hline & Baseline (2017) & $635(54.1 \%)$ & 539 (45.9\%) & & \\
\hline \multicolumn{6}{|c|}{ Summer schools } \\
\hline \multirow[t]{2}{*}{2014} & Participants & $16(69.6 \%)$ & $7(30.4 \%)$ & 0.27 & .869 \\
\hline & Baseline (2014) & 200 (68\%) & $94(32 \%)$ & & \\
\hline \multirow[t]{2}{*}{2016} & Participants & 15 (78.9\%) & $4(21.1 \%)$ & 0.58 & .446 \\
\hline & Baseline (2016) & $123(71.5 \%)$ & 49 (28.5\%) & & \\
\hline \multicolumn{6}{|c|}{ Grants $^{a}$} \\
\hline \multirow[t]{2}{*}{2015} & Grant recipients & 22 (81.5\%) & $5(18.5 \%)$ & 8.69 & .003 \\
\hline & Baseline (2015) & $617(53.5 \%)$ & $536(46.5 \%)$ & & \\
\hline \multirow[t]{2}{*}{2016} & Grant recipients & $14(73.7 \%)$ & $5(26.3 \%)$ & 3.16 & .075 \\
\hline & Baseline (2016) & 609 (53.5\%) & $529(46.5 \%)$ & & \\
\hline \multirow[t]{2}{*}{2017} & Grant recipients & 17 (70.8\%) & $7(29.2 \%)$ & 2.77 & .096 \\
\hline & Baseline (2017) & 635 (54.1\%) & 539 (45.9\%) & & \\
\hline
\end{tabular}

${ }^{a}$ Because membership information was provided to us from an earlier date than grants were awarded, some grant recipients did not appear among members from the same year, and therefore they are not presented in the table. 


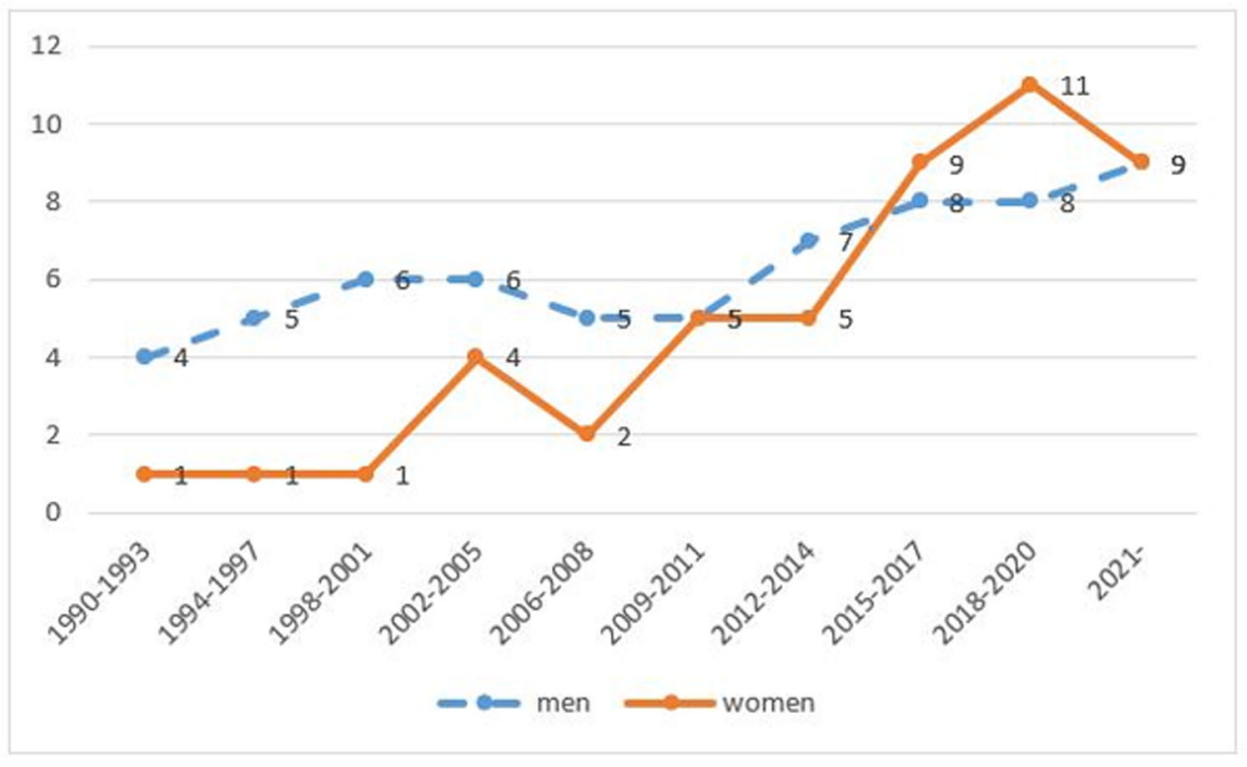

FIGURE 3 Gender distribution in EJSP Editorial Boards between 1990 and 2020

We compared presentation types of men and women not to the general baseline of membership, but to participating members. We found no differences (i.e., neither over-, nor underrepresentation) in thematic and poster presentations compared to the gender ratio of conference participants, but we found an underrepresentation of women and an overrepresentation of men in symposium presentations, which means that male attendants were more likely to present in symposia than female attendants (see Table 2).

At the 2017 General Meeting in Granada, there was no difference in participation between men and women in general, and in any of the membership categories. However, in presentation type, women were underrepresented and men overrepresented in symposia, while women were overrepresented in blitz presentations. No statistical difference was identified in poster presentations (see Table 2).

In 2015, 106 members ( 69 women and 37 men) participated in small and medium-sized meetings. Women were overrepresented and men underrepresented in these meetings compared to their ratio in membership. However, this was not the case in 2016 and 2017, when only 45 ( 23 women and 22 men) and 77 (48 women and 29 men) members participated in the meetings, respectively, and there was no overrepresentation of either men or women.

Out of 75 participants in the Lisbon Summer School in 2014, only 23 were members of EASP, and out of 63 participants in the Exeter Summer School in 2016, 19 were members of EASP. In both years, the summer schools were predominantly composed of women, which was proportional to (i.e., not statistically different from) the gender ratio of postgraduate membership.

There were 27 grants awarded to EASP members in 2015 in three categories, 19 grants in 2016 in five categories and 24 grants awarded in 2017 in four categories. As Table 2 shows, in 2015 women received more grants than their ratio in baseline membership would suggest, but the difference was not significant in either 2016 or 2017.

\subsubsection{Distinction and influence}

Between 1990 and 2018, 93 people were appointed for positions in the Editorial Board of EJSP (i.e., Chief Editors and Associate Editors combined), 39 (41.9\%) of these were filled by women and 54 (58.1\%) by men. Of the 14 chief editors over the period, five (35.7\%) were women and nine (64.3\%) were men. However, compared to the gender ratio within the Editorial Board between 1990 and 2008, the gender setup has been more equal since 2009 (see Figure 3, the figure includes information of the Editorial Board of 2021, discussed in 'Patterns after 2018' in more detail).

The situation with the European Review of Social Psychology is similar, but not identical (see Figure 4). Forty-four (33\%) of the total 133 positions were held by women and $89(67 \%)$ held by men over the years. However, the most recent board, appointed in 2020 has a larger proportion of women, 17 (60.7\%) women and 11 (39.3\%) men.

The Executive Committee consisted almost exclusively of men until the 1990s. This changed in 1996 and 1999, but again, from 2002 to 2008 , men outnumbered women. A notable change in the last four ECs (2011-2017) is that it has had a slight majority of women, with the latest elected Committee (2020) having a clear majority of women (see Figure 5). It must be noted that out of the total of 19 presidents of EASP, only two were women.

The Early Career Best Manuscript award was introduced in 2003 to the first author of an EJSP article. Out of the 14 awards given out between 2003 and 2017, 10 (71.4\%) were received by women and 4 (28.6\%) by men. While the numbers are too low for a meaningful comparison, this is roughly identical to the gender ratio of postgraduate members (71.8\% women, $28.2 \%$ men).

Between 1984 and 2020, 73 people received awards from EASP (i.e., Jaspars, Codol, Lewin, Tajfel awards, and the Moscovici award introduced in 2017). Put together, men outnumber women among EASP 


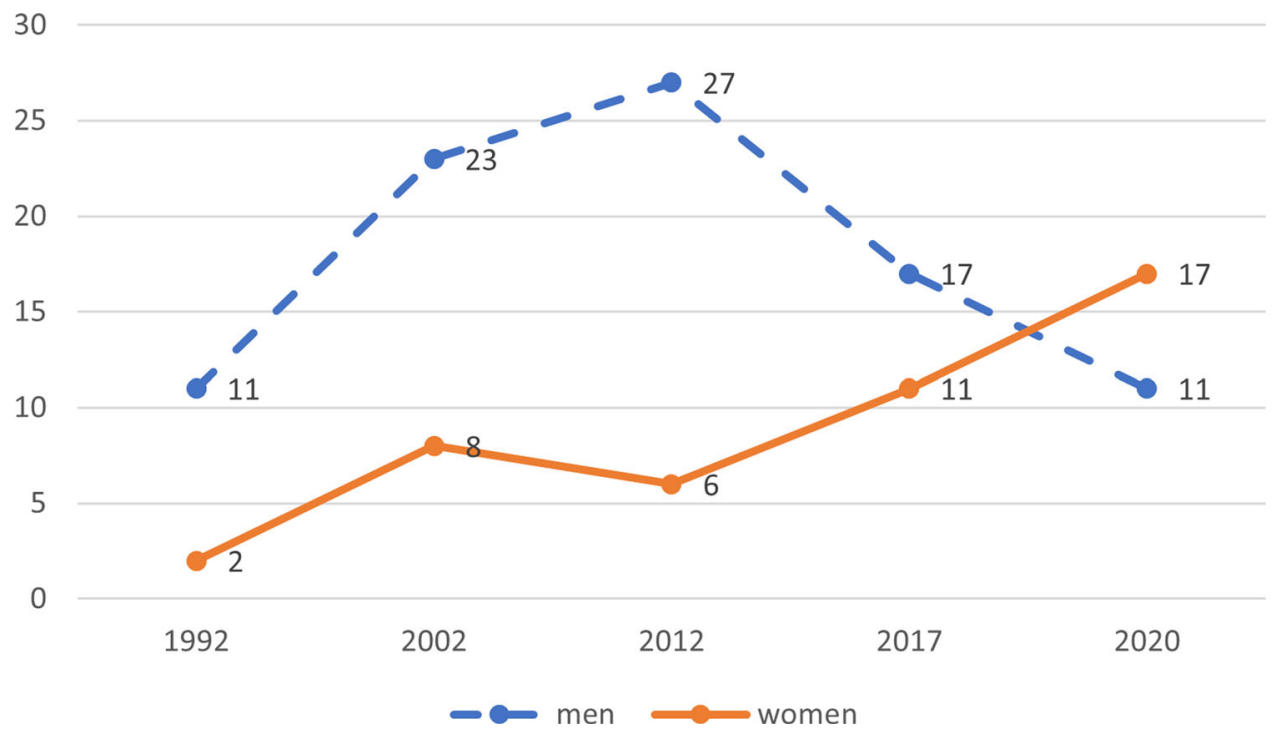

FIGURE 4 Gender distribution in ERSP Editorial Boards between 1990 and 2020

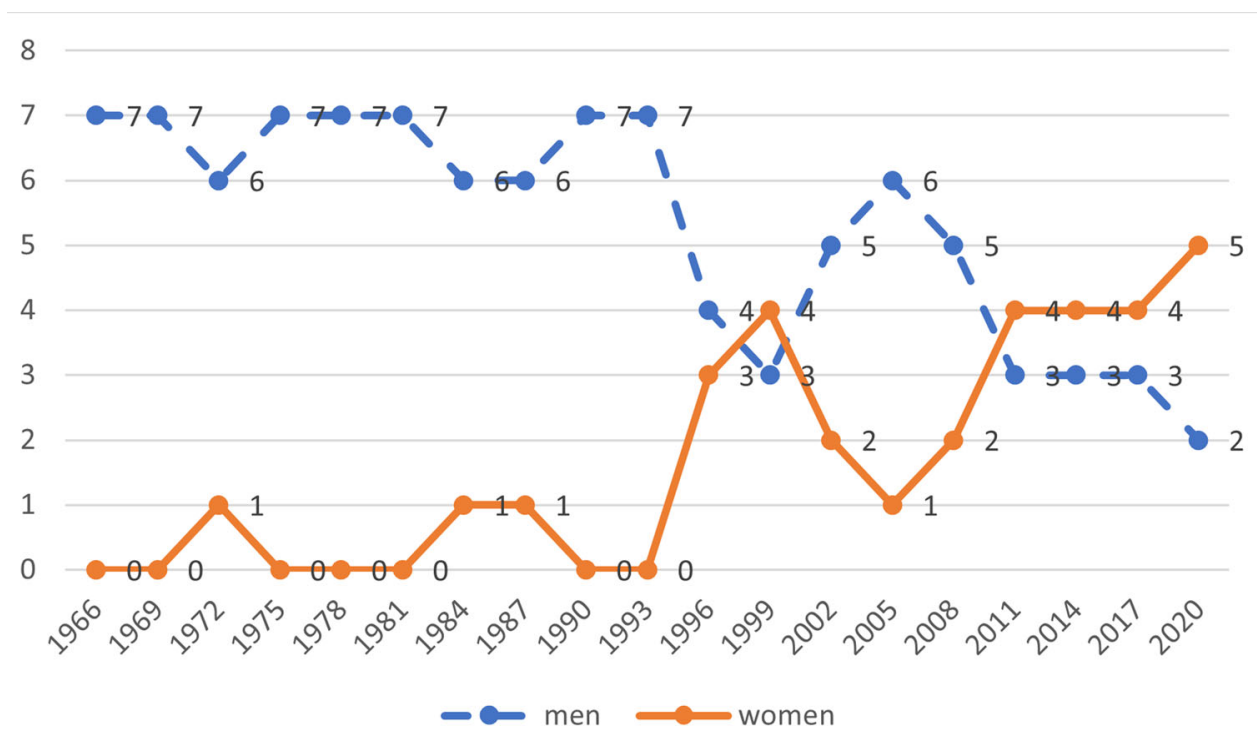

FIGURE 5 Gender distribution in EC membership between 1966 and 2020

award recipients (see Table 3). Although the numbers are small, this is clearly discrepant with the gender make-up of the membership. Perhaps the clearest indication of this discrepancy can be seen in the allocation of the Tajfel medal-the most long-lasting and senior of all the

TAB LE 3 Award recipients between 1984 and 20120 by gender (without The Early Career Best Manuscript award)

\begin{tabular}{lcr|} 
& Women & \multicolumn{1}{c|}{ Men } \\
\hline Award recipients (1984-2002) & $2(18.2 \%)$ & $9(81.8 \%)$ \\
\hline Award recipients (2005-2020) & $17(27.9 \%)$ & $44(72.1 \%)$ \\
\hline Total & $19(26.4 \%)$ & $53(73.6 \%)$ \\
\hline
\end{tabular}

awards: out of 13 recipients in total, only three were women, in 1993, in 2011 and in 2020.

We can identify roughly equal number of male and female first authors in publications published in the flagship journals of EASP. Between 2011 and 2020, EJSP published 776 articles. Out of these articles, 397 (52\%) papers were identified as written by a female first author and 367 (48\%) by a male first author, and we could not identify the gender of 12 first authors. The number of female and male first authors is somewhat less equal in the case of ERSP, which is also the higher impact journal of EASP, publishing review papers rather than primary research. Between 2011 and 2020, 87 papers were published in the journal, of which 37 (43\%) were written by a female first author and $50(57 \%)$ by a male first author. 


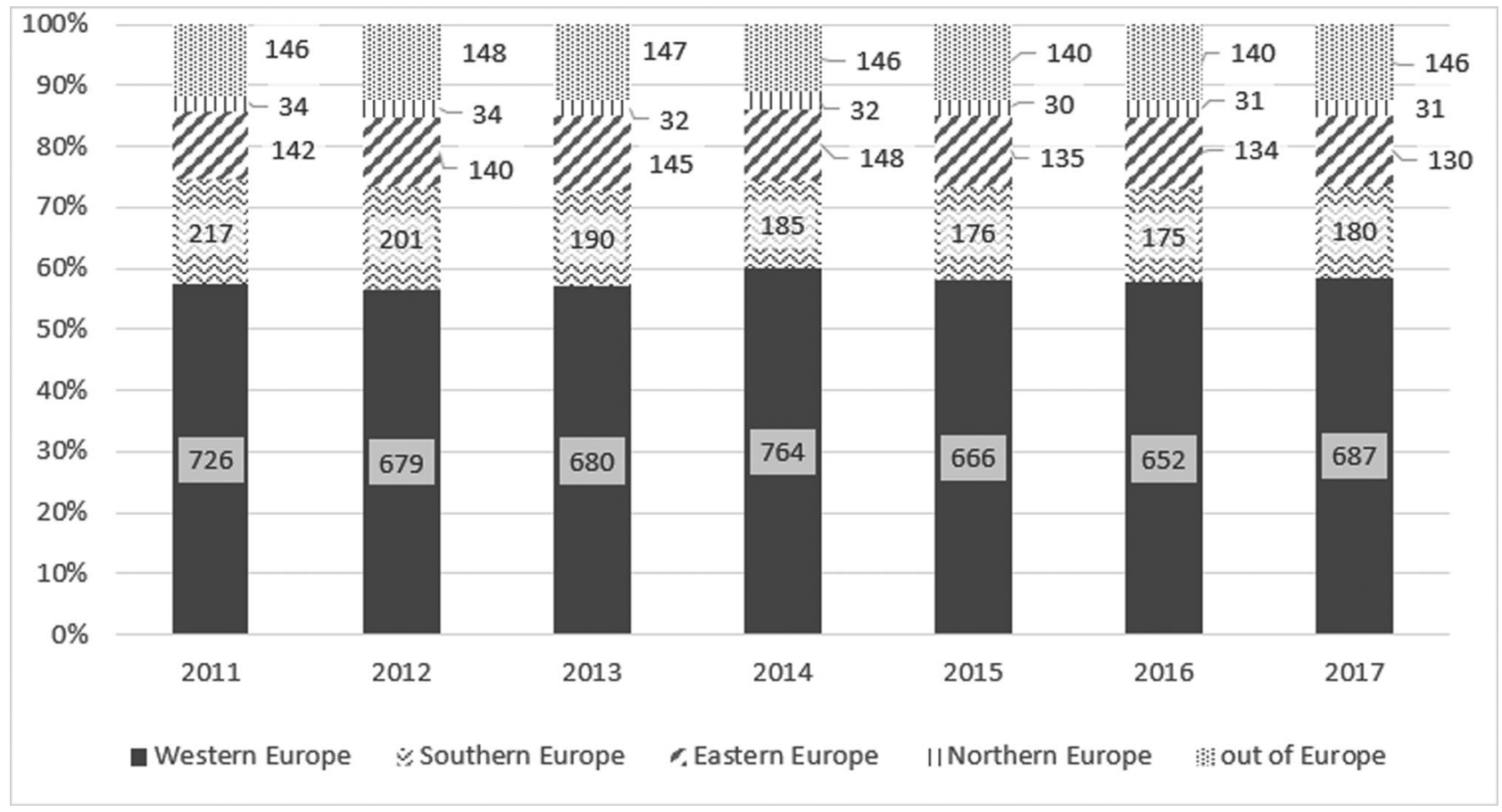

FIGURE 6 Regional distribution of the membership between 2011 and 2017

\subsection{Regional diversity}

\subsection{1 | Membership}

Although EASP members work in 44 countries, the regional distribution reflects the dominance of just a few countries in Western Europe. In 2017, out of 1174 members, 58.5\% were affiliated with institutions in Western Europe, 15.3\% in Southern Europe, 11.1\% in Eastern Europe, $2.6 \%$ in Northern Europe and 12.4\% outside Europe. These figures have remained relatively stable between 2011 and 2017 (see Figure 6).

By breaking down these figures to countries, we can see that a small number of countries dominate. In Western Europe, $71.6 \%$ of the regional total is made up of social psychologists working in the UK, Germany and the Netherlands. In Southern Europe, 76.1\% of the regional total work in Italy and Spain. In Eastern Europe, people working in Poland make up $50.8 \%$ of the regional total. Members from outside Europe work in the USA, Australia, Israel and Canada, that is, anglophone and Eurocentric countries of the world, making up $89.7 \%$ of the non-European members. Although information about specific countries and specific regions are important for any intervention strategies, in order to highlight the central issue, we examine the levels of inclusion based on just two regions, members working in Western Europe versus European countries that are outside Western Europe, leaving out members from outside Europe all together.

In the different categories of membership, discrepancies are particularly accentuated at the postgraduate level (see Figure 7). The vast majority of postgraduate members are affiliated with a university in
Western Europe, but the regional distribution becomes more proportionate among full members (see Figure 7). Comparing postgraduate members from these two regions, in 2011, $75.9 \%$ of them were from Western Europe versus 24.1\% from non-Western European countries (see Figure 7). Importantly, both the number and the proportion of nonWestern European postgraduates declined between 2011 and 2017.

\subsection{2 | Participation}

Differences between the participation in different events and grant schemes by region is highly uneven and presented in Table 4. At the 2014 General Meeting in Amsterdam more Western European members participated than non-Western European members. When this is compared to the regional ratio of membership in 2014, Western Europeans are even significantly overrepresented at the meeting compared to their already much higher baseline ratio. This overrepresentation was significant among postgraduate and full members when analysed separately. Again, we analysed presentation type not against the general baseline, but against the ratio of attendees (already underrepresenting the regions of non-Western Europe), and found that while Western European members were overrepresented in symposia and thematic sessions, participation was only proportional to the regions in the poster sessions.

In contrast, at the 2017 General meeting in Granada, we did not identify a statistically significant overrepresentation of Western Europeans on any levels. However, analysing presentation types we found that Western Europeans were overrepresented in symposia talks, 
TA B LE 4 Comparison of participation by region in general meetings (based on presentation type), in small and medium-sized group meetings, summer schools and grant schemes between 2014 and 2017

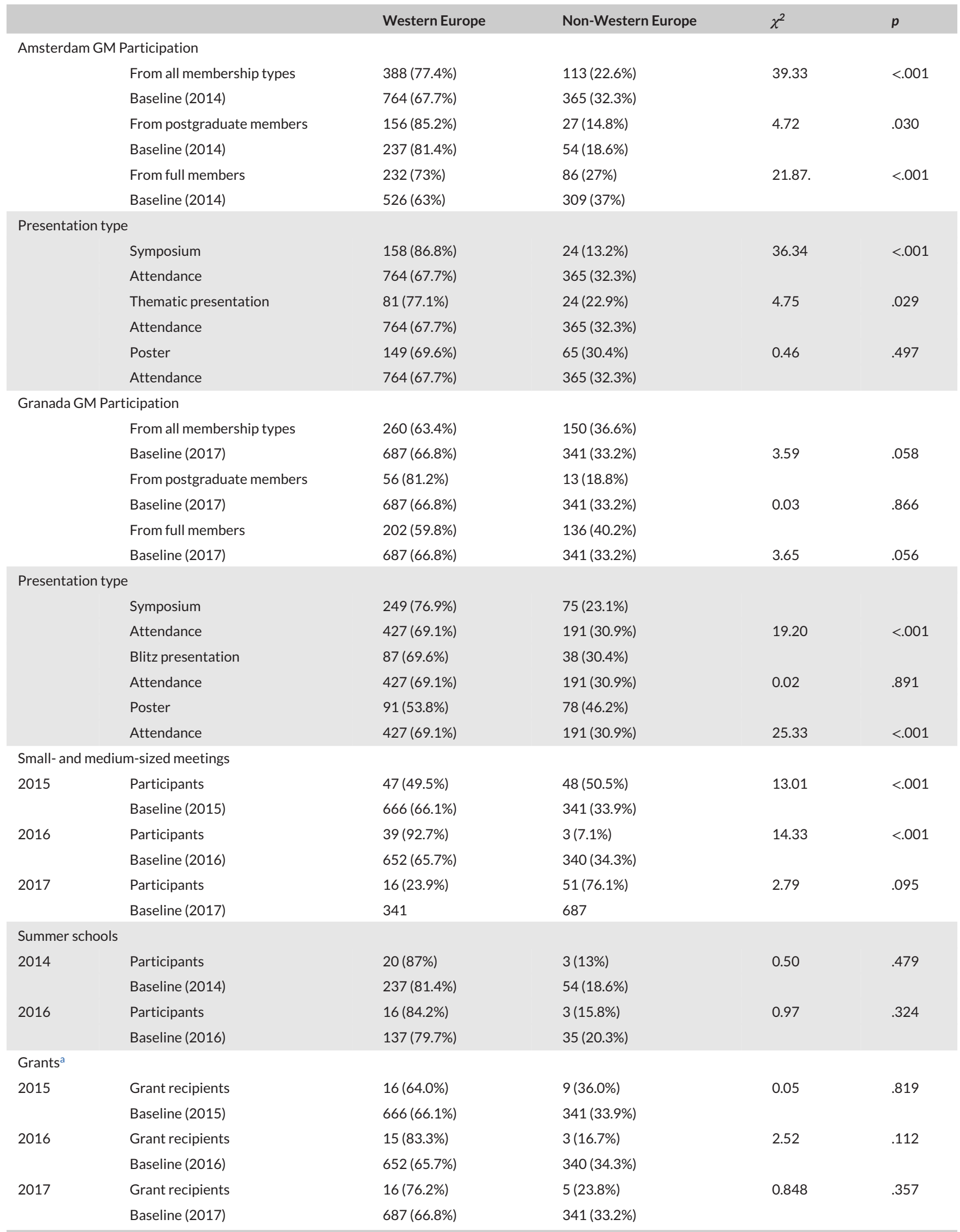

${ }^{a}$ We worked with the number of grants given to members in each year, but it is possible that some non-members also received grants that are not indicated in Table 4. 


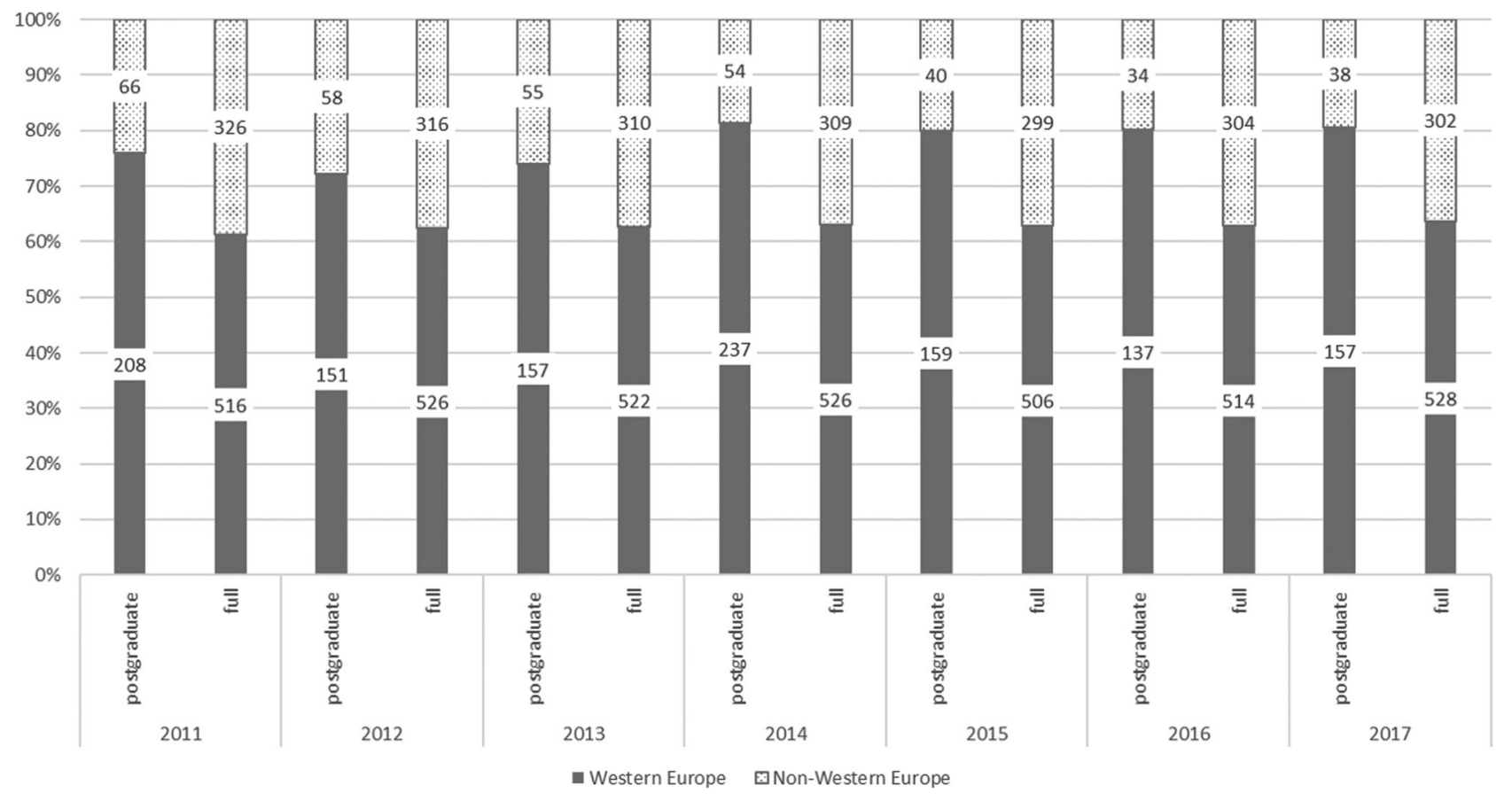

FIGURE 7 Region and membership status between 2011 and 2017

while they were underrepresented in poster presentations, and no differences were found in blitz presentations (see Table 4).

Interestingly, in the small and medium-sized meetings in 2015, members from the Western European region were underrepresented compared to the baseline of that year. It must be noted that out of the seven meetings four took place outside Western Europe in that year. The pattern was different in $\mathbf{2 0 1 6}$ when all three meetings were held in Western Europe, resulting in an overrepresentation of participants from Western Europe compared to the baseline of the membership ratio. In 2017 there was no difference in attendance from Western and non-Western Europe at small and medium size meetings.

EASP organised all together 18 summer schools in its history: twelve in Western Europe, five in Southern Europe and one in Eastern Europe. If we look specifically at the Lisbon Summer School in 2014 and the Exeter Summer School in 2016, the ratio of Western versus nonWestern participants was not significantly different from the proportion of EASP postgraduate members in the given year.

In 2015, 25 grants, in 2016, 18 grants and in 2017, 21 grants were awarded. In all of these years, the awards were awarded proportionally to members from Western and non-Western Europe compared to the baseline.

\subsubsection{Distinction and influence}

As opposed to gender, the regional representation within the EJSP Editorial Board (chief editors and associate editors combined) shows an increasing level of disproportionality. With fewer members, the small number of non-Western European members seemed more even between 1994 and 2008. The gap widened as the number of West- ern European board members increased more than the number of nonWestern European members since 2009 (see Figure 8). However, the Editorial Board appointed in 2021 changed this pattern, which resulted in more non-Western European members than Western Europeans. Additionally, there are two board members from outside Europe (from New Zealand and South Africa).

The regional distribution of editors and members of the Editorial Board of ERSP has been even more disproportional (see Figure 9). Between 1992 and 2020 at five-year intervals, the highest proportion of editors working in non-Western Europe was at the start. Thereafter, editors from Western Europe and out of Europe always comprised the absolute majority of members.

The Executive Committee has consisted predominantly of members from Western Europe since the foundation of EASP (see Figure 10). The Executive Committee from 2020 consists of four members from Western Europe, and two members from non-Western European countries and one from outside of Europe. It is also noteworthy that all 19 EASP presidents of the Association's history were scholars affiliated with a Western European institution.

Among EASP award recipients, there have always been more Western than non-Western European members (see Table 5). The most junior award (Early Career Best Manuscript award) has never been awarded to a researcher from a country outside Western Europe (in line with the low number of first authors in EJSP, see next paragraph). The vast majority of EASP awards went to people working in Western Europe. The most senior Tajfel award has been received by ten scholars from Western Europe, one from Southern Europe, and one from outside Europe.

Looking into the authorship in the two journals of the Association, the pattern indicates striking differences between scholars from 


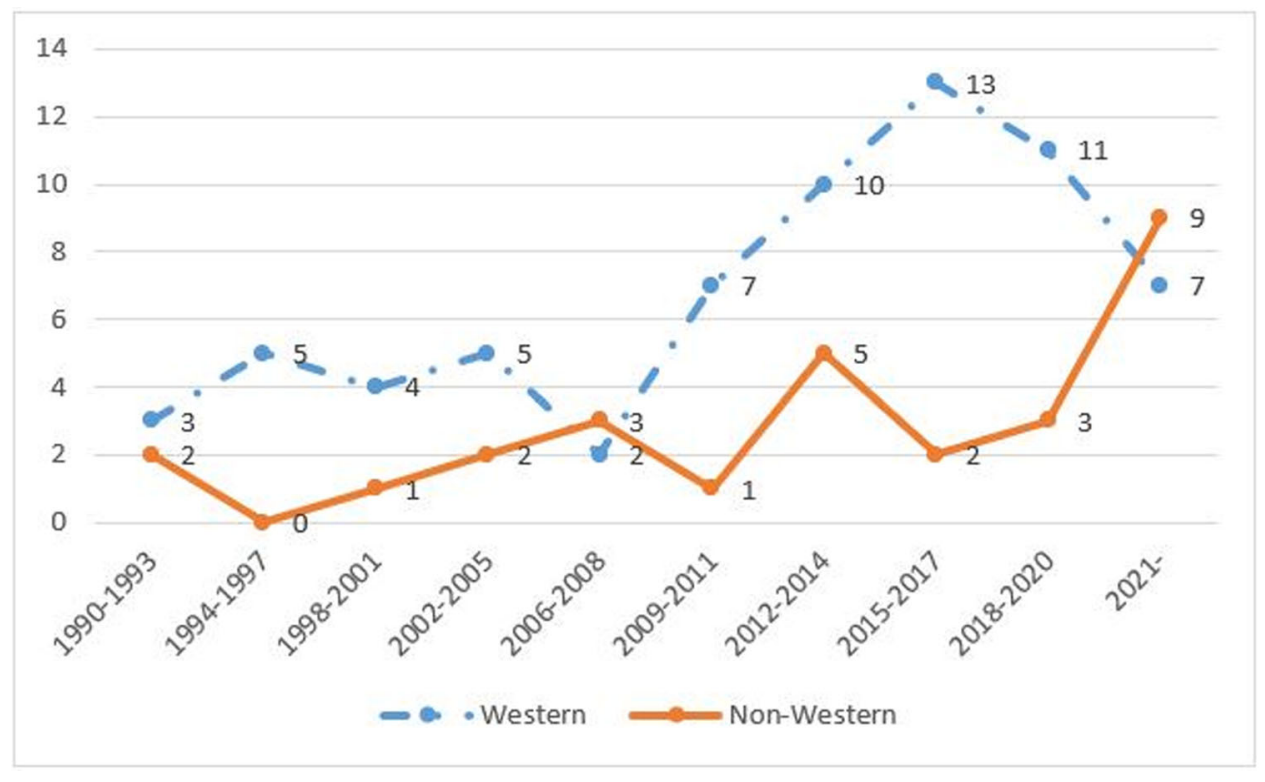

FIGURE 8 Regional distribution in EJSP Editorial Boards between 1990 and 2020

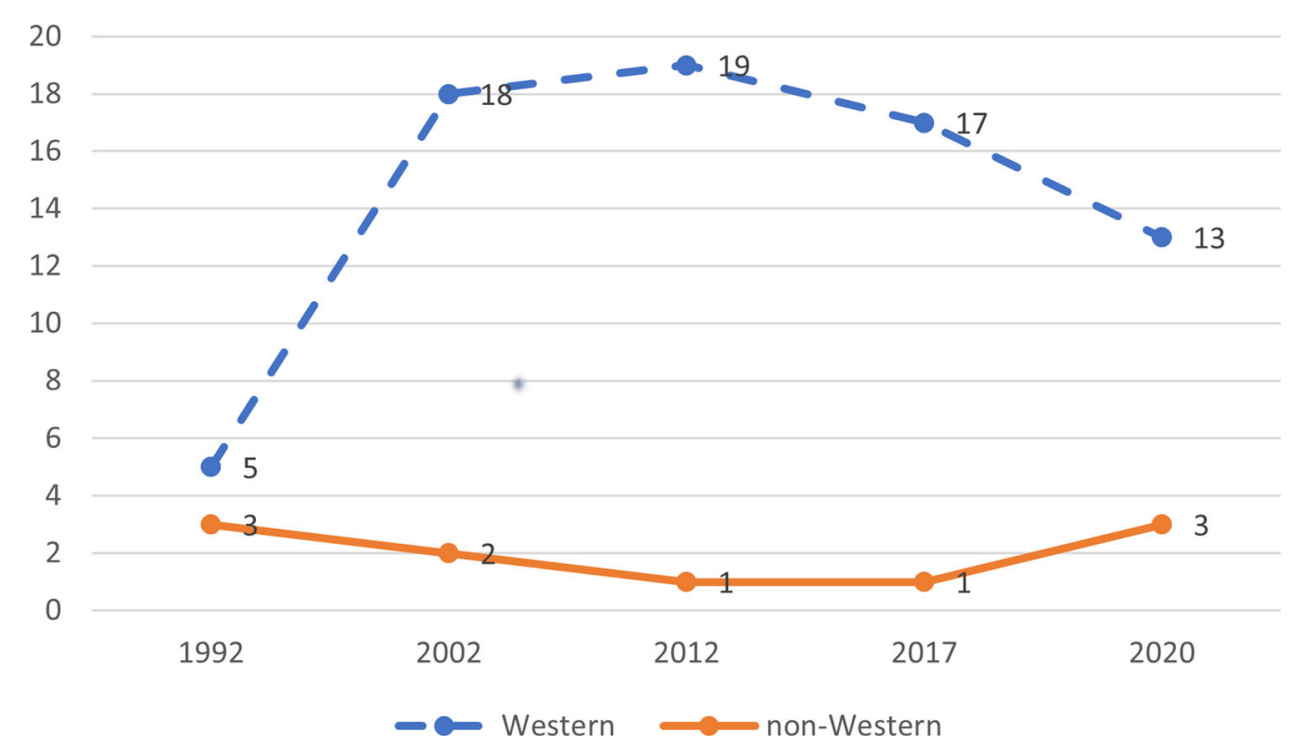

FIGURE 9 Regional distribution in ERSP Editorial Boards between 1990 and 2020

different regions as first authors. Between 2011 and 2020, EJSP published 369 (47\%) papers from first authors from Western European

TAB LE 5 Award recipients between 1984 and 2020 by region (without The Early Career Best Manuscript award, and without members out of Europe)

\begin{tabular}{lll} 
& $\begin{array}{l}\text { Western } \\
\text { European }\end{array}$ & $\begin{array}{l}\text { Non-Western } \\
\text { European }\end{array}$ \\
\hline Award recipients (1984-2002) & $9(90 \%)$ & $1(10 \%)$ \\
\hline Award recipients (2005-2020) & $45(81.8 \%)$ & $10(18.2 \%)$ \\
\hline Total & $54(83.1 \%)$ & $11(16.9 \%)$ \\
\hline
\end{tabular}

institutions, 271 (35\%) papers from countries outside Europe, that is, from anglophone countries and Israel, whereas only 109 (14\%) papers from authors from European institutions outside Western Europe. In addition, 33 (4\%) papers were written by authors from countries outside Europe that are not the typical countries where EASP members come from. These authors were affiliated with institutions in nonEnglish-speaking and mostly non-WEIRD countries. In case of ERSP, the results were even more disproportional: between 2011 and 2020, 51 (59\%) papers were written by first authors from Western Europe, 30 papers $(34 \%)$ by first authors of anglophone countries outside Europe or Israel and only six (7\%) by European authors outside Western Europe. 


\section{${ }^{14}$ WILEY $\curvearrowleft \circlearrowleft$}

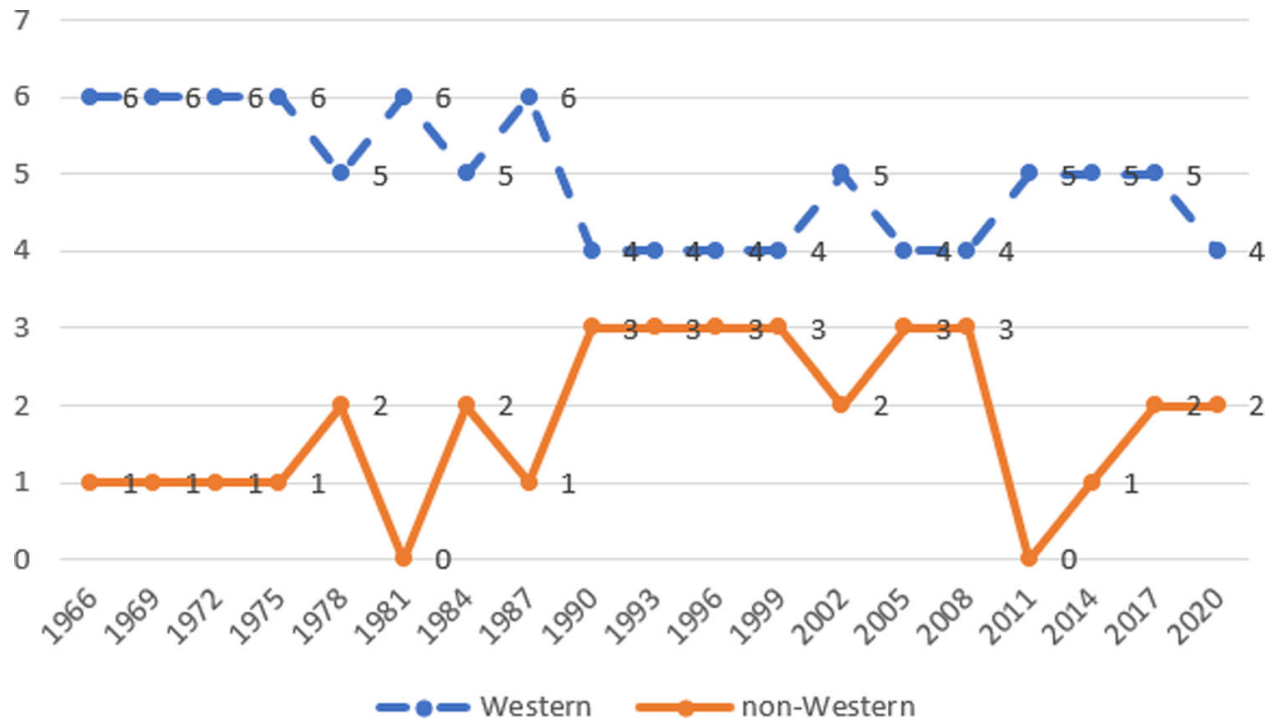

FIGURE 10 Region in EC membership between 1966 and 2020

\subsection{Patterns after 2018}

In 2018, the Executive Committee issued its Code of Conduct which states that 'EASP is committed to the philosophy of equality of opportunity and treatment for all members, regardless of gender, gender identity, race, ethnic origin, religion, age, marital status, sexual orientation, disabilities, or any other reason not related to scientific merit' (EASP, 2018). The Diversity and Scientific Integrity Statement focuses on achieving and maintaining a diverse membership, promoting the involvement of members from underrepresented regions and providing opportunities for financial support to members.

In accordance with the new policy, meeting organisers have to account for the diversity of their meetings, and accordingly, organisers submit their reports with information about inclusiveness. Most reports mentioned the gender ratio of participants, and listed the countries where participants came from; however, this was mostly done without mentioning their numbers or ratio. In 2018, five (three in Western Europe, two outside Western Europe), and in 2019, seven (five in Western, two in non-Western Europe and one outside of Europe) meetings were organised. In 2020, all meetings had to be cancelled due to the COVID-19 pandemic. We obtained more detailed, anonymised data-beyond the public reports-from eight of these (three from 2018 and five from 2019). In these eight meetings, in 2018, out of 66 EASP member participants, 45 (68.2\%) were women and 21 (31.8\%) men, and in 2019, out of 75 EASP members, 40 (53.3\%) were women and 35 (46.6\%) men. In sum, there was a tendency for more women to attend the meetings than men; however, considering the higher number of female postgraduate members, this does not necessarily indicate overrepresentation. From the perspective of regional diversity, in 2018 out of 66 EASP member participants, 40 (60.6\%) were from Western Europe, 19 (28.7\%) from non-Western Europe and 7 (10.6\%) from out of Europe. In 2019, out of 75 EASP member participants, 42 (56\%) were from Western Europe, 14 (18.6\%) of them from non-Western Europe and 19 (25.3\%) of them from out of Europe. These ratios suggest that the reports listing the countries may reflect diversity accurately, but overlook the issue of representation.

In the Zurich Summer School of 2018, 43 (78.2\%) women and 12 (21.8\%) men participated, 27 (49\%) of them from Western Europe, 17 (31\%) from non-Western Europe and 11 (20\%) of them from out of Europe. In 2020, Surrey Summer School that was held as a virtual event, 47 (63.4\%) women and 17 (26.6\%) men participated, 34 (52.3\%) were from Western Europe, 21 (32.3\%) from non-Western Europe and 10 (15.4\%) of them from out of Europe.

Between 2018 and 2020, out of 70 grants, 41 (59\%) were received by women and 29 (41\%) by men. In terms of region, 48 (69\%) grants were received by people from Western European countries, while 22 (31\%) were received by people from non-Western European countries.

In the current Editorial Board of EJSP (2021-2023), there are nine (50\%) women and nine (50\%) men and the board reflects a high regional diversity: seven (39\%) members are from Western Europe, nine (50\%) form non-Western European countries and two (11\%) from outside Europe. This increased regional diversity is in line with the Editorial statement, which states that one of the most important part of their vision for the Journal was to create a truly diverse Editorial Board, not only in terms of gender and region, but also in terms of skills and expertise (Noor et al., 2021).

These numbers fit into the trends that we identified for the period between 2011 and 2017. They indicate an increase in gender diversity, with a growing number of women participating in the events organised by EASP. The rate of female attendance may be proportional to their higher rate within the membership, especially because early career academics may be more active in participating in these events and grant schemes. In terms of regional diversity, we see an improvement in the case of summer schools, which is an extremely important tool for achieving change for the future of the organisation and future generations of social psychologists; however, we continue to see low participation of members from underrepresented regions in meetings. 
The higher ratio of women receiving grants compared to men is noteworthy, but it may also be proportionate to the general ratio of male and female members in the organisation. Although the number of grants offered to scholars outside Western Europe is higher than in previous years, the gap remains quite large: more than twice as many Western European members received a grant from the organisation in 2018 than non-Western European members. This is problematic, not because it is disproportional to the membership, but because it clearly suggests that grants are not used as a tool to narrow the gap between advantaged and disadvantaged regions; in fact they may continue to contribute to these asymmetries.

\section{DISCUSSION}

\section{1 | Gender}

In terms of gender diversity, there has been much progress over the years. From an Association which, at its origins, was dominated by men, and where all senior positions (on Editorial Boards, on the EC) were occupied by men, EASP has become more gender equal. Women are in a clear majority among postgraduate members and continue to represent a slight majority in the overall membership. Women have been in the majority on the EJSP Editorial Board in the past three years and in the EC for the past six years. Despite the presence and acknowledgement of women on many levels, we can identify a glass ceiling effect in the highest prestige areas, in the domains of distinction as suggested by awards, in the positions of the most influence, such as in the presidency.

The diminishing presence of women in the hierarchy is especially striking if we consider that they are in a clear majority at the entry level, but drop out to a greater degree before becoming full members. In this respect the pipeline metaphor may be more accurate than the glass ceiling effect and even offer an explanation for the decreasing number of women towards the top. This metaphor suggests that men travel smoothly through the pipeline, and thus, end up dominating the field, whereas the pipeline is 'leaky' for women, so they steadily fall out on every level (Clark, 2005). Postgraduate membership can only be maintained for four years, which may not be enough for everybody to complete their PhD studies, especially if this period coincides with starting a family, creating more challenges for women than for men to finish within the short time frame (Evans et al., 2008). Furthermore, full membership is granted to those who have an international publication, which may be more difficult to achieve within the four-year period for women because of both direct and indirect obstacles, such as taking on more responsibilities at work (Heijstra et al. 2017), or lack of confidence in academic promotion (Baker, 2010). Although men and women attend conferences proportionally, men are more likely to participate in the higher-prestige format compared to women. Despite recent improvements, the most prestigious awards are less often offered to women, and the ERSP Editorial Board had been dominated by men. Only in 2020 were both of these imbalances overcome.
The glass-ceiling effect may also be a reflection of tokenism (i.e., mobility limited to only some members of a disadvantaged group to advantaged positions, Laws, 1975). Although there are opportunities that come from being a token, it also comes with a number of drawbacks, such as lack of identification and belonging, which may discourage women from striving for high prestige (Peters et al., 2012b). Furthermore, tokenism confirms the illusion of diversity and inclusion from the perspective of the advantaged, so it decreases motivations for social change (Wright, 1997).

Therefore, in order to achieve higher gender equality, efforts of inclusion need to be (and appear to be) genuine, driven by the conviction that science can benefit from a fairer inclusion of women and their scientific contribution. The reality of the glass-ceiling effect may communicate mixed messages towards women in this respect. Therefore, even when women are equally represented in higher positions, gender bias continues to exist, and women continue to face challenges in the way they are perceived, evaluated and treated. Moreover, the belief that gender equality is already achieved can create a new barrier to achieving real gender equality (Begeny et al., 2020), similarly to the way that modern racism (i.e., the belief that racism is no longer a problem) can contribute to maintaining racial hierarchies and discrimination (Brief et al., 2000). Finally, it must be noted that our data are unable to inform us whether the progress concerning gender equality comes from adequate measures implemented by EASP, or from larger structural changes in academia and women's higher presence overall.

\section{2 | Region}

Despite efforts for a broader inclusion from early days of the Association (see Tajfel, 1972), EASP is and has always been predominantly an association of individuals working in Western Europe. This disproportionality has not changed over time, if anything, we can note an increase. For example, the ratio of non-Western European postgraduates has declined in the examined period between 2011 and 2017. This is not a promising pattern in terms of increasing the representation of non-Westerners in EASP for the coming years. Existing divisions of Europe continue to be reflected in the organisation despite efforts made by its leadership. This suggests either that efforts are not sufficient or not chosen well to overcome these challenges or that inequalities are reproduced to such a degree that the measures introduced by EASP cannot compensate for their growing influence.

The low levels of participation and influence reflect the low level of membership from members working outside Western Europe, but even compared to their disproportionately low baseline, they are underrepresented when it comes to activities, support and recognition. The lack of recognition and representation in positions of influence of members from outside Western Europe in the history of the Association speaks to a deep-rooted problem. Taking the example of the ERSP Editorial Board, over $90 \%$ of the board consists of members from Germany, the Netherlands and the English-speaking world (by which we mean the UK, USA, Canada and Australia-the last three countries accounting for all the non-European Editorial Board members throughout ERSP's 
history). Since 1997 to the present day, this 'triad' has constituted a minimum of $77.4 \%$ (24/31 in 2007) and a maximum of $93.9 \%(31 / 33$ in 2012) of Board members. The comparison of the Editorial Boards of EJSP and ERSP indicates the outcome of two different approaches and suggests that they lead to different outcomes. An earlier editorial statement of EJSP already emphasised the importance of diversity (Prisin \& Vignoles, 2015), and accordingly, managed to achieve a gender, but not yet a regional, balance in its Editorial Board. In contrast, ERSP strives only for excellence in its editorial statement ${ }^{3}$ and consists predominantly of Western European editors and editors from anglophone countries outside Europe. Again, we do not know whether these differences are indeed in a causal relationship with the diversity outcome, but they indicate that there is no diversity without an effort to achieve it.

In the context of 'publish or perish', the striking disproportion of getting published in the flagship journals of the Association for people working in different regions reflects a severe problem for social psychology and for EASP, specifically. These publications are the cornerstone of building an academic career and receiving recognition. Chief editors are appointed by the Executive Committee and EASP members receive free copies of the journals, thus publishing in these journals is highly prestigious and recognised as a scientific accomplishment. The difference between the two journals adds another layer to this issue. ERSP is the higher-impact journal, thus the difference in publishing papers by non-Western authors (and by women) indicates the tendency that diversity is more attainable at lower levels of prestige.

In conclusion, it is not a glass ceiling effect when it comes to regional representation, but something more like a glass labyrinth (Eagly \& Carli, 2007), as problems of regional diversity are present on all levels of the hierarchy. There is reason for cautious optimism if we look at the most recent period of the history of EASP, since the release of its Diversity Report in 2017. We can recognise the effectiveness of some attempts: for example, in the year when meetings were organised evenly across regions, the overrepresentation of Western Europeans disappeared. Since 2017 when meeting organisers make an effort to be more inclusive, the underrepresentation of scholars from non-Western European countries diminished. This type of data and the short period of time cannot support the view that there is a causal link between the location of the meeting or the efforts for inclusion and diversity, so these tendencies should be critically evaluated in the years to come.

\section{3 | Intersectionality}

Issues of regional and gender diversity are interconnected and embedded in other structural inequalities, and they are unlikely to be solved

\footnotetext{
${ }^{3}$ The aims and scope of ERSP specify the following 'It provides an outlet for substantial, theory-based reviews of empirical work addressing the full range of topics covered by the field of social psychology. Potential authorship is international, and papers are edited with the help of distinguished, international editorial board.' https://www.tandfonline.com/action/ journallnformation?show=aimsScope\&journalCode=pers20.
}

as isolated issues. Feminist psychology suggested that the inclusion of women in all areas and ranks of psychology may have been achieved, but improvements requiring structural changes have been less successful and remained more controversial, such as, for example, the inclusion of women of colour and the representation of women living in poverty (for a review, see Baker, 2006). Relatedly, efforts for gender equality have not addressed the structural inequalities embedded in current racial and cultural hegemonies that put gender inequalities of marginalised communities outside the focus of the discipline (Kurtiş \& Adams, 2015).

Our data suggest that the intersection of region and gender produce some paradoxical outcomes. Although we may expect that female scholars in countries with more traditional gender roles face additional obstacles, however, it seems that women from Western Europe drop out from the Association following their postgraduate period to a greater degree than women from other regions. One speculation for this is that where academia is more competitive, women are at a greater disadvantage than in regions where academic positions are easier to attain and there is a larger pay-gap between the for-profit sector and academia. Future research should offer a more thorough examination of the intersectional influence of region and gender as well as other social categories.

\section{4 | Limitations}

Our analysis is based on a case study of EASP, which limits the generalisability of our findings. Moreover, our analysis was highly restricted by the availability of data that influenced the type and depth of analyses that we could conduct. Importantly, our analysis was limited to gender and region and did not extend to other domains of diversity. We acknowledge that this is a very limited view on the issue of diversity, and there are other important domains to consider. Sexual orientation, gender identity, race, ethnicity, immigrant status and religious affiliation are all domains that affect whether an international organisation can include the experiences and expertise of researchers with different backgrounds. EASP as an organisation does not reflect the racial and ethnic diversity that characterises Europe, neither in membership, nor in any levels of participation, recognition and influence. As we do not have access to data on racial and ethnic representation within the organisation, nor about representation within the academic discipline of social psychology, the root of the problem cannot clearly be determined. However, the deeper structural problems regarding racism and inequalities within European societies (European Commission, 2019) and our understanding about the neoliberal academic context that contributes to the exacerbation of inequalities (Hanafi, 2016) suggest that these problems emerge outside the organisation, and EASP is unable to adequately address these challenges. Future analysis should focus on these problems, especially considering that there is a growing number of ethnic and racial minority students in higher education (Claeys-Kulik et al., 2019); therefore, questions need to be raised about their inclusion in social psychological research, and in EASP, specifically. 
We used affiliation as the proxy for region which we believe is the most important indicator of regional diversity. However, it does not acknowledge the potential role of researchers who come from different countries, especially if they have existing connections with academics from their country of origin or previous workplaces (see Jöns, 2009; Saxenian, 2005). We recognise that these ties are invaluable for increasing diversity, but the current analysis could not account for their influence. Secondly, the lack of information on country of origin masks the phenomenon of 'brain drain' (see Cervantes \& Guellec, 2002; Saravia \& Miranda, 2004), which is an important obstacle to increasing regional diversity. The relevance of understanding this phenomenon is that it can highlight an important and paradoxical problem. Namely, when opportunities are created for people coming from underrepresented regions (or groups), these opportunities often enable individual mobility only. However, individual mobility does not necessarily benefit the larger group or lead to structural change; in fact, it can lead to an increase of differences due to brain-drain. Our data cannot answer the question why academics outside Western Europe have more difficulty in being recognised without emigrating to Western European institutions, but we suggest that this should be an important consideration for all measures promoting diversity.

In our analysis, we lumped together all European countries outside Western Europe. This enabled us to highlight the problems connected to the dominance of a few Western European countries. However, this approach did not allow us to present interregional differences. Although we think that some challenges are shared across underrepresented regions, such as the status of academic institutions and language barriers, there are also important differences between them. Importantly, financial opportunities and the social-political contexts are highly different across countries. We acknowledge that not being able to address these cross-regional differences is a limitation of the current analysis, and diversity efforts need to look critically at contextual differences as well.

We have no data at all relating to the situation outside the Association. We are in no position to say how many social psychologists work in Europe, nor information about who they are and what kind of research they do. We do not know why people do or do not join, participate or else leave the Association. In particular, we do not know if it is an issue of motivation (they do not want to be part of this community) or of practicality (they are unable to be part of the community). Any new policy to increase diversity, if it is to be effective, should investigate these questions as well.

\section{5 | CONCLUSIONS AND RECOMMENDATIONS}

Our findings point to the fact that much has improved in terms of gender representation since the 1990s when the boards of EASP journals and of its Executive Committee were almost exclusively male. The Association is clearly moving in the right direction. But equally clearly, there is no room for complacency. On the one hand, there is a dramatic drop-out of women when they finish their PhDs. On the other hand, the most prestigious positions in EASP remain male dominated. The fact that only three of the 13 recipients of the top award (the Tajfel Prize) and only two of the 19 Presidents of the Association have been women is clearly cause for concern.

When we turn to regional representation, there is less room for optimism, more reason for pessimism. With the exception of the Editorial Board of EJSP (where, recently, strenuous efforts have been made to improve geographical spread), there is little sign of improvement since the 1990s. Many of the figures are shocking: only $14 \%$ of articles in EJSP have first authors who are from parts of Europe other than the West; only $13.2 \%$ and $23.1 \%$ of symposium presenters at the 2014 and 2017 General meetings were similarly located; the Association has never had a Tajfel Prize winner or a President from Eastern Europe. Even this underrepresents the problem. In many ways (especially when it comes to the prizes and the Presidency) the European Association is a Western European or indeed a North Western European Association. It is undoubtedly time for a change.

It should be stressed that these findings are intended less as a final word than as the start of a conversation and a spur to further research. Our analyses serve to map patterns of representation, but they do little to explain them. We do not know why women drop out after their PhDs. We do not know why there are so few Eastern Europeans in the Association (and in its representative positions). Is it simply that there are fewer social psychologists in such countries? Is it that there are many but that they do not orient to EASP? And, if the latter, is that because of practical issues like cost and language, is it because they subscribe to theoretical traditions that they feel are marginalised in the Association, or is it something else?

Perhaps most critically, it is important to reiterate that parity of representation is a necessary, but certainly not a sufficient condition of equality in any organisation. The notion that equal representation is the same as equality can actually hold back change (Begeny et al., 2020). The treatment and experience of minorities within academic institutions can involve everything from under-citation (Cardel et al., 2020) to explicit violence (Towl \& Walker, 2019). The topics that women study can be under-valued and under-rewarded (Hanafi \& Arvanitis, 2014). We need to investigate whether and how these processes operate within EASP.

When we began the work reported in this article, it was understood that it would be the first step in an ongoing process. We would first examine the figures to establish whether there were issues that needed to be followed up within EASP. If we discovered underrepresentation in the areas we were addressing, we would go on both to explore further areas and undertake in-depth studies to identify the bases of such underrepresentation. We believe that our analyses indeed establish the basis for further work and that this is more urgent than ever. To put it slightly differently, having shown that there are pressing issues of unequal representation we now need to uncover the barriers to equality so we can devise a systematic and effective programme of action to address them. However, the need to improve our understanding is not an argument to defer action to some unspecified future date.

A commitment to a better representation of all European regions would entail rethinking some basic principles and answering some difficult questions. Should this academic organisation include members who are already integrated into international academia (with requirements for entry resembling that of a closed club) or reach out to those 
who work within the discipline but do not have international connections and publish locally? The first reflects the current conditions of EASP membership. The latter would indicate that European social psychology can include researchers (a) not yet embedded in international academia, (b) using methods that are different from the mainstream, (c) working on themes that are meaningful locally or in other regions, but less prevalent in Western Europe. Decisions around these issues would resonate with a critical re-evaluation of local knowledge production and current hegemonies in social psychological science (i.e., the accepted topics, methods and language of knowledge production; for a similar critique of the lack of inclusion of Arab language science, see Hanafi \& Arvanitis, 2014).

In summary, first, EASP and other academic associations must recognise and address the various dimensions of privilege that lead some demographics within the Association to be over-representedfrom personal connections, working with academically well-networked supervisors, access to funding, speaking English fluently, and much more. All forms of academic privilege need to be challenged in an attempt to increase diversity (Maher \& Tetreault, 2009). Second, diversity processes must be embedded at all levels and in all activities of the Association. Among other things, this can be realised by a Diversity Officer within the Executive Committee, which has been introduced in 2020; a Diversity sub-committee of the EC chaired by the Diversity Officer; a pool of funding for diversity research relating to the Association; diversity criteria for all activities of the Association and for any funding provided by the Association; a full diversity audit presented to every General Meeting of the Association. Third, we need to embed the values of inclusion and diversity at the very heart of the Association and to make clear that actions that cut across these values are incompatible with membership of EASP. In these ways, EASP will be in a position to realise its original vision of being an Association for all social psychologists in all of Europe and beyond.

\section{ACKNOWLEDGEMENTS}

We would like to thank the Executive Committee of EASP, Manuela Baretto (president) Jean-Claude Croizet, Kai Sassenberg, Mara Cadinu, Ernestine Gordijn, Torun Lindholm and Daniël Wigboldus for initiating a diversity analysis that provided the basis of our current article.

\section{CONFLICT OF INTEREST}

This project is based on The Diversity Project, which was supported by the European Association of Social Psychology. We have no other conflict of interest to declare.

\section{ETHICAL STATEMENT}

We conducted only secondary data analysis, no primary data requiring ethical approval was collected for this study.

\section{REFERENCES}

Altbach, P. G., \& Knight, J. (2007). The internationalization of higher education: Motivations and realities. Journal of Studies in International Education, 11, 290-305. https://doi.org/10.1177/1028315307303542
Au, W. (2014). Hiding behind high-stakes testing: Meritocracy, objectivity and inequality in US education. International Education Journal: Comparative Perspectives, 12, 7-19.

Awesti, A., Flinders, M., \& Savigny, H. (2016). Pursuing the diversity and inclusion agenda: The PSA in the UK. European Political Science, 15, 508518. https://doi.org/10.1057/s41304-016-0073-8

Bagilhole, B., \& White, K. (2013). Generation and gender in academia. Palgrave Macmillan UK.

Baker, M. (2010). Career confidence and gendered expectations of academic promotion. Journal of Sociology, 46, 317-334. https://doi.org/10. 1177/1440783310371402

Baker, N. L. (2006). Feminist psychology in the service of women: Staying engaged without getting married. Psychology of Women Quarterly, 30, 114. https://doi.org/10.1111/j.1471-6402.2006.00257

Banaji, M. R., \& Greenwald, A. G. (2016). Blindspot: Hidden biases of good people. Delacorte Press.

Barreto, M. E., Ryan, M. K., \& Schmitt, M. T. (2009). The glass ceiling in the 21st century: Understanding barriers to gender equality. American Psychological Association. https://doi.org/10.1037/11863-000

Begeny, C. T., Ryan, M. K., Moss-Racusin, C. A., \& Ravetz, G. (2020). In some professions women have become well-represented, yet gender bias persists - Perpetuated by those who think it is not happening. Science Advances, 6, eaba7814. https://doi.rog/10.1126/sciadv.aba7814

Bian, L., Leslie, S. J., \& Cimpian, A. (2017). Gender stereotypes about intellectual ability emerge early and influence children's interests. Science, 355, 389-391. https://doi.org/10.1126/science.aah6524

Bian, L., Leslie, S. J., Murphy, M. C., \& Cimpian, A. (2018). Messages about brilliance undermine women's interest in educational and professional opportunities. Journal of Experimental Social Psychology, 76, 404-420. https://doi.org/10.1016/j.jesp.2017.11.006

Brief, A. P., Dietz, J., Cohen, R. R., Pugh, S. D., \& Vaslow, J. B. (2000). Just doing business: Modern racism and obedience to authority as explanations for employment discrimination. Organizational Behavior and Human Decision Processes, 81, 72-97. https://doi.org/10.1006/obhd.1999.2867

Cardel, M. I., Dhurandhar, E., Yarar-Fisher, C., Foster, M., Hidalgo, B., McClure, L. A., Pagoto, S., Brown, N., Pekmezi, D., Sharafeldin, N., Willig, A. L., \& Angelini, C. (2020). Turning chutes into ladders for women faculty: A review and roadmap for equity in academia. Journal of Women's Health, 29, 721-733. https://doi.org/10.1089/jwh.2019.8027

Cervantes, M., \& Guellec, D. (2002). The brain drain: Old myths, new realities. (Brain drain). OECD Observer, 40-43. Retrieved from http: //oecdobserver.org/news/archivestory.php/aid/673/The_brain_drain: Old myths, new_realities.html

Claeys-Kulik, A. L., Jørgensen, T. E., \& Stöber, H. (2019). Diversity, equity and inclusion in european higher education institutions: Results from the INVITED Project. European University Association.

Clark, B. J. (2005). Women and science careers: Leaky pipeline or gender filers. Gender and Education, 17, 369-386. https://doi.org/10.1080/ 09540250500145072

Derks, B., Rink, F., van Veelen, R., \& Manzi, F. (2018). EASP Meeting: Defeating the seven-headed dragon: An exploration into the complex self-maintaining system that causes gender inequality. Retrieved from https://www.easp.eu/news/itm/easp_meeting_defeating_the_seven headed_dragon_an_exploration_into_the_complex_self_maintaining system_that_causes_gender_inequality-786.html

Eagly, A. H., \& Carli, L. L. (2007). Woman and the labyrinth of leadership. Harvard Business Review, 85, 62-71. https://doi.org/10.1108/HRMID.2008. 04416AAD.004

Eagly, A. H., \& Miller, D. I. (2016). Scientific eminence: Where are the women? Perspectives on Psychological Science, 11, 899-904. https://doi. org/10.1177/1745691616663918

EASP. (2018). Code of conduct and diversity statement. Retrieved from https://www.easp.eu/events/coc/

Erickson, B. H., Albanese, P., \& Drakulic, S. (2000). Gender on a jagged edge: The security industry, its clients, and the reproduction and revision of 
gender. Work and Occupations, 27, 294-318. https://doi.org/10.1177/ 0730888400027003003

Ernst-Vintila, A., Alaya, D. B., de Rosa, A., \& Neculau, A. (2016). Do the shoemaker's children go barefoot? Diversity in social psychology and the two worldmaps of its diachronic evolution 5. Psihologia Sociala, 38, 125-132.

European Commission. (2019). Discrimination in the EU. Special Eurobarometer 493. Retrieved from https://ec.europa.eu/commfrontoffice/ publicopinion/index.cfm/survey/getsurveydetail/instruments/special/ surveyky/2251

European Commission. (2021). The EU values. Retrieved from https://ec. europa.eu/component-library/eu/about/eu-values/

Evans, E., Grant, C., \& Peskowitz, M. (2008). Mama, PhD: Women write about motherhood and academic life. Rutgers University Press.

Fleras, A. (2016). Theorizing micro-aggressions as racism 3.0: Shifting the discourse. Canadian Ethnic Studies, 48, 1-19. https://doi.org/10.1353/ ces.2016.0011

Gino, F., Wilmuth, C. A., \& Brooks, A. W. (2015). Compared to men, women view professional advancement as equally attainable, but less desirable. Proceedings of the National Academy of Sciences, 112, 12354-12359. https://doi.org/10.1073/pnas.1502567112

Giroux, H. (2015). Democracy in crisis, the specter of authoritarianism, and the future of higher education. Journal of Critical Scholarship on Higher Education and Student Affairs, 1, 101-113. Retrieved from https:// ecommons.luc.edu/cgi/viewcontent.cgi?article $=1001 \&$ context=jcshesa

Graumann, C. F. (1995). The origins of the EASP: Social psychology in Europe: The role of the European Association of Experimental Social Psychology, Retrieved from https://www.easp.eu/getmedia.php/_media/easp/ 201707/401v0-orig.pdf

Hanafi, S. (2016). Global knowledge production in the social sciences: A critical assessment. Sociologies in Dialogue, 2, 16-30. https://doi.org/10. 20336/sid.v2i1.29

Hanafi, S., \& Arvanitis, R. (2014). The marginalization of the Arab language in social science: Structural constraints and dependency by choice. Current Sociology, 62, 723-742. https://doi.org/10.1177/0011392114531504

Hegarty, P., \& Bruckmüller, S. (2013). Asymmetric explanations of group differences: Experimental evidence of Foucault's disciplinary power. Social and Personality Psychology Compass, 7, 176-186. https://doi.org/10. 1111/spc3.12017

Heijstra, T. M., Einarsdóttir, P., Pétursdóttir, G. M., \& Steinpórsdóttir, F. S. (2017). Testing the concept of academic housework in a European setting: Part of academic career-making or gendered barrier to the top? European Educational Research Journal, 16, 200-214. https://doi.org/10. $1177 / 1474904116668884$

Heinrich, J., Heine, S. J., \& Norenzayan, A. (2010). Most people are not weird. Nature, 466, 29. https://doi.org/10.1038/466029a

Henry, P. J. (2008). College sophomores in the laboratory redux: Influences of a narrow data base on social psychology's view of the nature of prejudice. Psychological Inquiry, 19, 49-71. https://doi.org/10.1080/ 10478400802049936

Hopkins, J. (2011). The role of learned societies in knowledge exchange and dissemination: The case of the Regional Studies Association, 1965-2005. History of Education, 40, 255-271. https://doi.org/10.1080/ 0046760X.2010.518161

Horvat, V. (2004). Brain drain: Threat to successful transition in South East Europe. Southeast European Politics, 5, 76-93. Retrieved from http://www.seep.ceu.hu/archives/issue51/horvat.pdf?iframe=true\& width $=100 \%$ \&height $=100 \%$

Jimenez, M. F., Laverty, T. M., Bombaci, S. P., Wilkins, K., Bennett, D. E., \& Pejchar, L. (2019). Underrepresented faculty play a disproportionate role in advancing diversity and inclusion. Nature Ecology \& Evolution, 3, 1030-1033. https://doi.org/10.1038/s41559-019-0911-5

Johnson, C. S., Smith, P. K., \& Wang, C. (2017). Sage on the stage: Women's representation at an academic conference. Personality and Social Psychology Bulletin, 43, 493-507. https://doi.org/10.1177/0146167216688213
Jöns, H. (2009). 'Brain circulation' and transnational knowledge networks: Studying long-term effects of academic mobility to Germany, 1954-2000. Global Networks, 9, 315-338. https://doi.org/10.1111/j. 1471-0374.2009.00256.x

Kurtiş, T., \& Adams, G. (2015). Decolonizing liberation: Toward a transnational feminist psychology. Journal of Social and Political Psychology, 3, 388-413. https://doi.org/10.5964/jspp.v3i1.326

Laws, J. L. (1975). The psychology of tokenism: An analysis. Sex Roles, 1, 5167.

Leslie, S. J., Cimpian, A., Meyer, M., \& Freeland, E. (2015). Expectations of brilliance underlie gender distributions across academic disciplines. Science, 347, 262-265. https://doi.org/10.1126/science.1261375

Losego, P., \& Arvanitis, R. (2008). Science in non-hegemonic countries. Revue d'Anthropologie des Connaissances, 2, 343-350. https://doi.org/10.3917/ rac.005.0343

Madera, J. M., Hebl, M. R., Dial, H., Martin, R., \& Valian, V. (2019). Raising doubt in letters of recommendation for academia: Gender differences and their impact. Journal of Business and Psychology, 34, 287-303. https: //doi.org/10.1007/s10869-018-9541-1

Maher, F. A., \& Tetreault, M. K. (2009). Diversity and privilege. Academe, 95 , 17-20.

Malat, J., Clark-Hitt, R., Burgess, D. J., Friedemann-Sanchez, G., \& Van Ryn, M. (2010). White doctors and nurses on racial inequality in health care in the USA: Whiteness and colour-blind racial ideology. Ethnic and Racial Studies, 33, 1431-1450. https://doi.org/10.1080/01419870903501970

Martin, P. Y. (2003). "Said and done" versus "saying and doing": Gendering practices, practicing gender at work. Gender \& Society, 17, 342-366. https://doi.org/10.1177/0891243203017003002

McGuire, W. J. (1967). Some impending reorientations in social psychology: Some thoughts provoked by Kenneth Ring. Journal of Experimental Social Psychology, 3, 124-139. https://doi.org/10.1016/0022-1031(67) 90017-0

Moscovici, C. (1997). Gendered spheres in Balzac's La Cousine Bette. International Journal of Politics, Culture, and Society, 10, 469-496. https://doi. org/10.1007/BF02098687

Noor, M., Suitner, C., \& Morton, T. (2021). Diversity: From people to knowledge and back again. European Journal of Social Psychology, 51, 1-4. https: //doi.org/10.1002/ejsp.2755

Peters, K., Ryan, M., Haslam, S. A., \& Fernandes, H. (2012a). Evidence that women's occupational disidentification is promoted by lack of fit with masculine occupational prototypes. Journal of Personnel Psychology, 11, 148-158. https://doi.org/10.1027/1866-5888/a000067

Peters, K., Ryan, M., Haslam, S. A., \& Fernandes, H. (2012b). To belong or not to belong: Evidence that women's occupational disidentification is promoted by lack of fit with masculine occupational prototypes. Journal of Personnel Psychology, 11, 148-158.

Razran, G. (1958). Psychology in communist countries other than the USSR. American Psychologist, 13, 177-178. https://doi.org/10.1037/h0039111

Ridgeway, C. L. (1997). Interaction and the conservation of gender inequality: Considering employment. American Sociological Review, 62, 218-235. https://doi.org/10.2307/2657301

Roth, L. M. (2004). Bringing clients back in: Homophily preferences and inequality on Wall Street. Sociological Quarterly, 45, 613-635. https://doi. org/10.1111/j.1533-8525.2004.tb02307.x

Rubini, M., \& Menegatti, M. (2014). Hindering women's careers in academia: Gender linguistic bias in personnel selection. Journal of Language and Social Psychology, 33, 632-650. https://doi.org/10.1177/ $0261927 \times 14542436$

Saab, R., Ayanian, A. H., \& Hawi, D. R. (2020). The status of Arabic social psychology: A review of 21st-century research articles. Social Psychological and Personality Science, 11, 917-927. https://doi.org/10.1177/ 1948550620925224

Saravia, N. G., \& Miranda, J. F. (2004). Plumbing the brain drain. Bulletin of the World Health Organization, 82, 608-615. 
Saxenian, A. (2005). From brain drain to brain circulation: Transnational communities and regional upgrading in India and China. Studies in Comparative International Development, 40, 35-61. https://doi.org/10.1007/ BF02686293

Sears, D. O. (1986). College sophomores in the laboratory: Influences of a narrow data base on social psychology's view of human nature. Journal of Personality and Social Psychology, 51, 515-530. https://doi.org/10.1037/ 0022-3514.51.3.515

Shen, H. (2013). Inequality quantified: Mind the gender gap. Nature, 495, 22-24. https://doi.org/10.1038/495022a

Stone, P. (2007). Opting out?: Why women really quit careers and head home University of California Press.

Tajfel, H. (1972). Some developments in European social psychology. European Journal of Social Psychology, 2, 307-322. https://doi.org/10.1002/ ejsp. 2420020307

Towl, G. J., \& Walker, T. (2019). Tackling sexual violence at universities: An international perspective. London: Routledge.

Valian, V. (2005). Beyond gender schemas: Improving the advancement of women in academia. Hypatia, 20, 198-213. https://doi.org/10.1111/j. 1527-2001.2005.tb00495.x

Van Avermaet, E. (2017). The history of the European Association of Social Psychology 1967-2017. Retrieved from https://www.easp.eu/history/

Van den Brink, M. (2010). Behind the scenes of science: Gender practices in the recruitment and selection of professors in the Netherlands. Amsterdam University Press.

Van den Brink, M., \& Benschop, Y. (2012). Slaying the seven-headed dragon: The quest for gender change in academia. Gender, Work \& Organization, 19, 71-92. https://doi.org/10.1111/j.1468-0432.2011.00566

Williams, J. C. (2005). The glass ceiling and the maternal wall in academia. New Directions for Higher Education, 130, 91-105. https:// doi.org/10.13140/RG.2.1.1387.1845 Retrieved from https://www. researchgate.net/profile/Joan_Williams4/publication/281034395_ The_Glass_Ceiling_and_the_Maternal_Wall_in_Academia/links/ 55d21c1e08ae7fb244f40fd7/The-Glass-Ceiling-and-the-MaternalWall-in-Academia.pdf

Wood, V., \& Sczeszny, S. (2017). Report on EASP Meeting: Gender roles in the future? Theoretical foundations and future research directions. Meeting Report. Retrieved from https://www.easp.eu/news/itm/ report_on_easp_meeting_gender_roles_in_the_future_theoretical_ foundations_and_future_research_directions-495.html

Wright, C., Thompson, S., \& Channer, Y. (2007). Out of place: Black women academics in British universities. Women's History Review, 16, 145-162. https://doi.org/10.1080/09612020601048704

Wright, S. C. (1997). Ambiguity, social influence, and collective action: Generating collective protest in response to tokenism. Personality and Social Psychology Bulletin, 23, 1277-1290. https://doi.org/10.1177/ 01461672972312005

Zajonc, R. B. (1957). Psychology in Poland: From M. Choynowski's "On the awakening of Polish psychology". American Psychologist, 12, 730-733. https://doi.org/10.1037/h0049204

How to cite this article: Nyúl, B, Lantos, NA, Reicher, SD, \& Kende, $A$. The limits of gender and regional diversity in the European Association of Social Psychology. European Journal of Social Psychology, 2021;1-20.

https://doi.org/10.1002/ejsp.2774
APPENDIX

Appendix A: Categorisation of countries into regions within Europe Western Europe

Austria

Belgium

France

Germany

Ireland

Luxembourg

Switzerland

The Netherlands

UK

Southern Europe

Greece

Italy

Portugal

Spain

Turkey

Eastern Europe

Albania

Bosnia/Herzegovina

Bulgaria

Croatia

Czech Republic

Estonia

Hungary

Latvia

Lithuania

North Macedonia

Moldova

Montenegro

Poland

Romania

Russia

Serbia

Slovakia

Slovenia

Ukraine

Northern Europe

Denmark

Finland

Norway

Sweden 